\title{
Interdicción de personas que sufren trastorno de dependencia a la cocaína
}

\author{
Hernán Corral Talciani*
}

\begin{abstract}
RESUMEN
La legislación chilena no provee un régimen especial para la interdicción de personas que sufren un trastorno de dependencia a sustancias, en especial a la cocaína, por lo que es necesario determinar si deben aplicarse las reglas propias de la interdicción por demencia o por prodigalidad para lograr una protección de estas personas y un resguardo para sus cónyuges y parientes. Después de un análisis de lo que debe entenderse por demencia y prodigalidad a la luz de los desarrollos del derecho civil comparado y de las declaraciones, convenciones internacionales y legislación especial sobre discapacidad mental, se concluye que un trastorno de cocaina puede dar lugar tanto a una interdicción por disipación como por demencia. Ante esta concurrencia de regimenes legales se plantea que el juez deberá resolver sobre la base de cuál se adecua mejor a las necesidades de protección del afectado.
\end{abstract}

Interdicción - demencia - disipación

Interdiction of people with cocaine dependence

\begin{abstract}
Chilean law does not provide special legal regime to custodianship of people who bave a substancerelated disorder, especially cocaine, and it is necessary to determine which rules apply: those of dementia or prodigality, for ensure protection of these people and a receipt for their spouses and relatives. After an analysis of what is meant by dementia and prodigality in the light of developments in civil law compared and declarations, international conventions and special legislation on mental disability, we conclude that a disorder of cocaine can lead to both: prodigality as dementia. Given this concurrence of legal regimes is argued that the judge must rule based on which is best suited to the protection needs of the affected.
\end{abstract}

Interdiction - dementia - dissipation

* Abogado, Doctor en Derecho, Profesor de Derecho Civil en la Facultad de Derecho de la Universidad de los Andes, Santiago de Chile. hcorral@uandes.cl

Artículo recibido el 24 de junio de 2011 y aceptado para su publicación por el Comité Editorial el 28 de octubre de 2011. 


\section{Planteamiento}

$\mathrm{F}$ rente a una persona mayor de edad que sufre de lo que en psiquiatría actual se conoce como trastorno de dependencia a sustancias, entre ellas la cocaína, se presentan problemas que preocupan fuertemente a su familia. Aunque existen momentos en los que, al menos desde lo externo, ella actúa normalmente y controla responsablemente sus actos, existen períodos en los que, obsesionada por la necesidad de obtener la sustancia o sumida en los efectos deformadores de la realidad producidos por el consumo, descuida no sólo su propia seguridad personal, sino la de sus seres más cercanos. Se niega a recibir tratamientos o elude su control y puede atentar contra su vida. No son pocos los que mueren por una sobredosis o un consumo de sustancias adulteradas. Se desprenden de todo su patrimonio, asumen deudas que luego no son capaces de pagar y que terminan repercutiendo en sus familiares, cometen delitos o cuasidelitos penales o civiles, y en general pierden las facultades para mantener el dominio de sus vidas.

Es natural que los familiares (padres, hermanos, cónyuge e hijos) intenten proteger a estas personas de la enfermedad que las afecta mediante las herramientas que les ofrece el ordenamiento civil. No obstante, y a diferencia de lo que sucede en sistemas legales comparados más actualizados, la situación de los que padecen estos trastornos no está considerada específicamente entre aquellas que facultan a sus familiares a pedir una declaración de interdicción y el nombramiento de un guardador que pueda darles la protección debida.

Las posibilidades legales que contempla la legislación civil chilena son dos: la declaración de interdicción por demencia y la declaración de interdicción por disipación o prodigalidad. Es posible señalar que estos regímenes están superados por los progresos actuales de la medicina y por fenómenos incapacitantes propios de las sociedades modernas (adicción a las drogas, adicción al juego, alzheimer, etc.) y que sería sensato, como se ha hecho en la mayoría de los países de cultura legal similar a la chilena, reformular completamente el sistema de protección de incapaces o discapacitados. No es ese el propósito directo de este trabajo, que no se plantea el tema desde el punto de vista de política legislativa ${ }^{1}$. Intentamos, en cambio, efectuar una interpretación o relectura de las reglas de la interdicción por demencia o por disipación para ver cómo pueden ser ellas aplicadas del modo más adecuado para resolver los acuciantes problemas que provoca la afección de trastornos de cocaína.

${ }^{1}$ No faltan las propuestas para modificar el régimen vigente, aunque ninguna asume el tema en toda su integridad. Pueden verse los siguientes proyectos de ley: "Modifica disposiciones que indica estableciendo un nuevo régimen respecto del curador ad litem" (Boletín No 5671-07, 3 de enero de 2008); "Modifica el Código Civil y otros textos legales en materia de cambio de denominación de la causal de incapacidad absoluta "demencia", por "discapacidad mental de grado grave o profunda"” (Boletín No 6247-07, 10 de diciembre de 2008); "Establece la autodesignación de curador en previsión de una futura discapacidad" (Boletín N No 6282-07, 17 de diciembre de 2008); "Establece incapacidad relativa respecto de las personas que sufran adicción a las drogas" (Boletín No 6532-25, 20 de mayo de 2009); "Modifica el Código Civil en materia de nombramiento de curador especial” (Boletín No 7041-07, 6 de julio de 2010). 
Se pretende determinar cuál de los regímenes vigentes es el que corresponde aplicar cuando se presenta la situación de una persona afectada por un trastorno de dependencia de sustancias, particularmente de la cocaína.

Comenzaremos por un análisis de la normativa y literatura jurídica sobre las dos formas de interdicción en el Código Civil chileno (II). Hecho lo anterior, se revisarán las tendencias de derecho comparado y de derecho internacional en materia de discapacidad mental y de anomalías del carácter que inciden en el comportamiento con relevancia jurídica (III), así como las actuales normativas nacionales que tienden a configurar una nueva mirada a la discapacidad por trastornos a la salud mental. Con ello se afirmará la forma en que debe entenderse hoy día la interdicción por demencia prevista en el Código Civil (IV).

Aclarada la interdicción por demencia, se procederá a determinar los requisitos propios de la interdicción por disipación (V).

Dando un nuevo paso, se tratará de ver si es posible que en una misma persona concurran los requisitos normativos tanto para la declaración de demencia como para la de la prodigalidad, y, si es así, cómo debería solucionarse esta concurrencia de normativas y cómo correspondería plantearlas procesalmente (VI).

Con esta determinación, se procederá a estudiar la situación de la persona que sufre trastornos relacionados con el consumo de cocaína, con consulta a los principales instrumentos de diagnóstico que utiliza la psiquiatría actual. Con ello se llegará a una conclusión sobre si en estos casos procede la interdicción por demencia, por disipación, o ambas (VII).

\section{DEMENCIA Y PRODIGALIDAD EN LA NORMATIVA Y DOCTRINA CHILENA}

\section{Caracterización de la demencia}

El Código Civil distingue entre personas dementes y disipadores calificando a los primeros de incapaces absolutos y a los segundos de incapaces relativos si se hallan bajo interdicción de administrar sus bienes (art. 1447 CC). El art. 456 CC dispone que si el adulto "se halla en un estado habitual de demencia deberá ser privado de la administración de sus bienes, aunque tenga intervalos lúcidos".

La doctrina chilena ha sostenido que la expresión que utiliza el Código: "demencia”, debe entenderse en su sentido amplio o lato que alude a todo tipo de enajenación mental. Luis Claro Solar señala de este modo: "Comprende la ley en la palabra demencia la enajenación mental bajo todas las formas en que pueda presentarse y en todos sus grados, cualquiera que sea el nombre que se le dé" ${ }^{2}$. Entiende por enajenación mental todo tipo de privación, debilitamiento de la capacidad de razonar o discernimiento: "Hizo, pues, bien el Código en no entrar en la enumeración de las diversas formas que puede presentar la

${ }^{2}$ Claro Solar, L., Explicaciones de Derecho Civil chileno y comparado, reimp. Editorial Jurídica de Chile, Bogotá, 1992, t. V, No 2420, p. 100. 
enajenación mental, incluyéndolas todas en la palabra demencia que se aplica a todo trastorno de la razón que impide a una persona tener la libre voluntad de obligarse y la responsabilidad de sus actos haciéndolo absolutamente incapaz" ${ }^{3}$. En el mismo sentido, aunque escribiendo ahora en la segunda mitad del siglo XX, Somarriva señala que "la expresión demente la toma nuestro Código en un sentido amplio, comprendiendo toda alteración mental que prive de razón a un individuo" 4 . Arturo Alessandri Besa, siguiendo a Claro Solar, dice que “la palabra 'demente' o 'loco' significa en el Código Civil aquella persona que está con sus facultades mentales alteradas, que padece de una enfermedad mental, cualquiera que sea su denominación técnica o sus características patológicas" ${ }^{5}$. Del mismo modo, enseña Ramos que "la doctrina estima unánimemente que demencia implica cualquier tipo de privación de la razón, sin importar cuál sea el nombre técnico de la enfermedad que la produce" 6 . Para Lyon debe añadirse la ineptitud para administrar competentemente lo suyo: "Es demente, y por consiguiente incapaz, aquella persona que, como consecuencia de una enfermedad mental, carece de la aptitud necesaria para administrar competentemente lo suyo"7.

La poca jurisprudencia que existe sobre el tema afirma también esta interpretación amplia de la demencia. Un fallo de la Corte de Concepción de 1896 sostuvo que, aun cuando la ley no define, para el caso de decretar la interdicción, quiénes son dementes, es indudable que designa con esta denominación, dados el motivo y objeto por que los somete a curatela, no sólo a los que por debilidad o desórdenes intelectuales, de carácter habitual, carecen en absoluto de razón, sino también a los que, por las mismas causas, no pueden dirigirse a sí mismos o administrar competentemente sus negocios. La Corte revocó el fallo de primera instancia que había denegado la interdicción por considerar que el demandado, si bien padecía una debilidad intelectual, no era demente (C. Concepción 27 agosto 1896, Gaceta de los Tribunales 1896, t. II, No 3.325, p. 613). La misma Corte ha reproducido esta misma doctrina en un fallo de 2008, insistiendo que "lo anterior permite concluir que la interpretación que debe darse a la expresión "demencia no es en su significado científico o técnico, sino que debe tomarse claramente en su sentido más amplio, más diverso [sic], esto

\footnotetext{
${ }^{3}$ Claro Solar, L., ob. cit., t. V, No 2420, p. 103.
}

${ }^{4}$ Somarriva Undurraga, M., Derecho de Familia, Nascimento, Santiago, 1963, No 769, p. 702. Igualmente, Rossel Saavedra, E., Manual de Derecho de Familia, Edit. Jurídica de Chile, $7^{\text {a }}$ edic. actualizada y corregida por María Dora Martinic y Graciela Weinstein, Santiago, 1993, No 532, p. 376. Meza Barros, R., Manual de

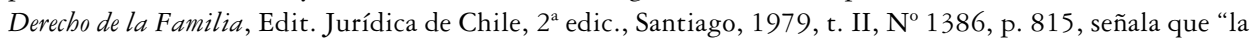
demencia, en el sentido legal, es la falta de razón, en términos que el sujeto no está en condiciones de apreciar el alcance de sus actos y carece consiguientemente de la aptitud para administrar por sí mismo sus negocios”.

5 Alessandri Besa, A., La nulidad y la rescisión en el Derecho Civil chileno, Edit. Jurídica de Chile, $3^{\text {a }}$ edic., Santiago, 2008, t. I, No 490, p. 432.

${ }^{6}$ Ramos Pazos, R., Derecho de Familia, Editorial Jurídica de Chile, 6a edic., Santiago, 2007, No 867 , p. 612 .

${ }^{7}$ Lyon Puelma, A., Personas naturales, Ediciones Universidad Católica de Chile, $3^{\text {a }}$ edic., Santiago, 2007, No 138, p. 179. En el mismo sentido, Frigerio, C. y Pizarro, A., "Incapacidad civil y representación legal del enfermo mental recluido en un establecimiento psiquiátrico", en Familia y personas, Enrique Barros coord., Editorial Jurídica de Chile, Santiago, 1991, p. 44: "Lo importante para la ciencia jurídica es que la enfermedad psíquica sea de tal naturaleza que impida al sujeto dirigirse a sí mismo y administrar competentemente sus negocios". 
es, en sentido de enfermedad mental" (C. Concepción, 10 de junio de 2008, rol № 2402008, Base de Jurisprudencia de Legal Publishing $\mathrm{N}^{\circ}$ 39216).

Siguiendo los conocimientos psiquiátricos de la época, Claro Solar agrega que en la demencia se comprende tanto "la falta completa de la inteligencia", como las "sensaciones que constituyen el idiotismo innato y la imbecilidad", así también "la demencia propiamente dicha caracterizada por la debilidad o nulidad de las facultades intelectuales y de

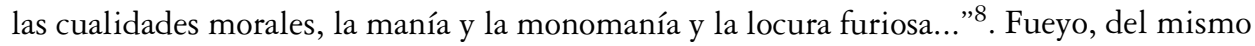
modo, apunta que "se incluyen, pues, el idiotismo, la imbecilidad, la debilidad mental y todas las formas de locura, tranquilas o furiosas. Todas son afecciones que dan por resultado en el individuo la pérdida de la razón"'.

Los jueces no están llamados, dice Claro Solar, a investigar más o menos científicamente la influencia de tal o cual lesión cerebral, "sino de saber, en el hecho, en un caso dado, si tal persona, cuya interdicción se pide, conserva o no una inteligencia suficiente de los negocios de la vida civil y la aptitud conveniente para la marcha ordinaria de la administración de un patrimonio" ${ }^{10}$.

No bastan ni la avanzada edad, ni la embriaguez habitual ni otros vicios contrarios a las conveniencias sociales. Las rarezas o extravagancias no pueden justificar la demencia, si no hay limitación o privación del uso de la razón: "Mientras el individuo no está privado del uso de su razón, depende de su voluntad apartarse del precipicio a que lo conducen sus pasiones desordenadas; y la ley no ha tratado de acudir en protección de una voluntad depravada, sino de la falta de voluntad producida por la enajenación mental..."11.

Claro Solar analiza especialmente el caso de la embriaguez; en principio, señala que "mientras el ebrio conserva el uso de su razón, desde que deja de estar en estado de ebriedad, no puede evidentemente ser considerado como un demente, e interdicto como tal" ${ }^{2}$. Pero advierte que "la embriaguez puede ser uno de los efectos de la locura o llevar a ella, constituyendo una monomanía, la dipsomanía o necesidad irresistible de beber, que puede complicarse con accesos más o menos frecuentes de delirio, delirium tremens y llegando a constituir esta embriaguez o alcoholismo un estado habitual, justificaría, sin duda, la interdicción por demencia" ${ }^{\prime 3}$.

Para proceder a la interdicción es necesario que la demencia sea habitual ${ }^{14}$. La habitualidad no significa irreversibilidad o permanencia absoluta y continua de la enajenación. Basta que el estado de demencia "constituya el modo de ser ordinario del insano"15. La habitualidad debe alcanzar no sólo a la enfermedad mental, sino a la incapacidad para administrar los

\footnotetext{
${ }^{8}$ Claro Solar, L., ob. cit., t. V, No 2420, p. 103, cita tratados de medicina legal de la época.

${ }^{9}$ Fueyo Laneri, F., Derecho Civil VI: Derecho de Familia, Universo, Santiago, 1959, t. III, No 1294, p. 727.

${ }^{10}$ Claro Solar, L., ob. cit., t. V, N $\mathrm{N}^{\circ} 2421$, p. 104.

${ }^{11}$ Claro Solar, L., ob. cit., t. V, No 2425, p. 107.

${ }^{12}$ Claro Solar, L., ob. cit., t. V, N 2426, p. 108.

${ }^{13}$ Claro Solar, L., ob. cit., t. V, No 2426, p. 108.

${ }^{14}$ Aunque la habitualidad no es necesaria para considerar incapaz absoluto al que padece demencia: cfr. Lyon, A., ob. cit., N $\mathrm{N}^{\circ} 138$, p. 180.

${ }^{15}$ Claro Solar, L., ob. cit., t. V, N 2422, p. 104.
} 
bienes del demente ${ }^{16}$. Por eso, "un desarreglo pasajero de las facultades intelectuales, que podría provenir, por ejemplo, de una violenta conmoción cerebral, de una enfermedad, no sería causa suficiente para la interdicción, aunque durara algún tiempo" ${ }^{17}$; lo mismo destacan Somarriva: "una alteración pasajera de las facultades mentales de una persona no autoriza su interdicción"18, y Fueyo: "se descartan los estados pasajeros... Como sería el caso del ebrio, del sonámbulo, del hipnotizado, y de los que sufren de delirio febril o de un aturdimiento causado por un fuerte golpe"19. Ramos añade el caso del "drogado"20. Esto, sin perjuicio de que se discuta si en el momento en que el ebrio, el drogado, el hipnotizado, se encuentran bajo los efectos enajenantes deban ser o no considerados dementes, aunque no para declararlos interdictos sino para pedir la nulidad del acto realizado en ese estado ${ }^{21}$.

Pero, por otro lado, el intervalo lúcido no obsta a la interdicción si el que lo logra es una persona con demencia habitual. Para Claro Solar el intervalo lúcido no es una simple apariencia o momento fugaz de cordura, sino un período más o menos largo en que el demente deja de ser afectado por su enajenación, una especie de curación pasajera, "una intermisión tan claramente marcada, que sea enteramente semejante al restablecimiento de la salud" 22 .

La jurisprudencia ha precisado que la demanda de interdicción debe ser notificada al supuesto demente y no a un curador ad litem. Si la demencia es notoria debe primero emplazarse al demandado por la notificación de la demanda y trabada la litis podrá nombrarse curador para el pleito (C. Rancagua, $1^{\circ}$ de septiembre de 2005, rol No 629-2005, Legal Publishing $\mathrm{N}^{\mathrm{o}}$ 32859). Asimismo, la Corte de Valparaíso anuló la sentencia que acoge la excepción dilatoria de falta de capacidad del demandante por haber declarado éste padecer una enfermedad cerebral y ser incapaz por demencia; la Corte señala que la interdicción sólo podía tramitarse en un juicio ordinario y no en un procedimiento incidental: "Que las consideraciones precedentes abonan, de un modo absoluto, la necesidad que la demencia de una persona y su consecuencial interdicción sólo pueden determinarse por sentencia judicial recaída en un juicio de lato conocimiento, el que por su propia naturaleza da oportunidades a las partes de exponer ampliamente sus respectivas posiciones, de alegar fundadamente sus derechos y de acreditar los hechos en que se apoyan. La incidencia en cuestión no puede reemplazar al procedimiento ordinario y no constituye una debida garantía para los contendientes" (C. Valparaíso, 10 de agosto de 1988, Gaceta Jurídica No 111, p. 44).

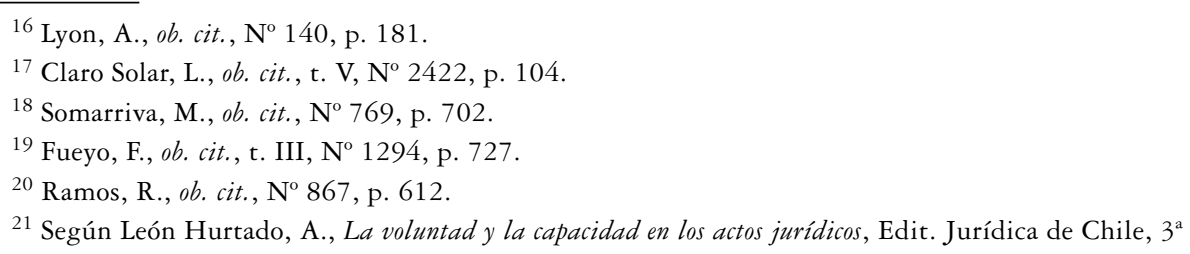
edic., Santiago, 1979, pp. 300-301, si se trata de una privación transitoria de la razón no puede hablarse de demencia, aunque el acto igualmente podría ser impugnado por falta de voluntad o consentimiento. Larraín Ríos, H., Lecciones de Derecho Civil, Editorial Jurídica de Chile, Santiago, 1994, pp. 294-295, piensa lo mismo aunque señala que la discusión puede ser importante para la aplicación de la responsabilidad civil que el art. 2318 CC atribuye al ebrio. En este mismo sentido se pronuncia Barcia Lehmann, R., Lecciones de Derecho Civil chileno, Editorial Jurídica de Chile, Santiago, 2007, t. I, p. 71.

${ }^{22}$ Claro Solar, L., ob. cit., t. V, No 2423, p. 104, siguiendo a D'Aguesseau. 


\section{Caracterización de la prodigalidad}

El Código Civil no define la disipación o prodigalidad. Sólo indica que "la disipación deberá probarse por hechos repetidos de dilapidación que manifiesten una falta total de prudencia" y que "El juego habitual en que se arriesguen porciones considerables del patrimonio, donaciones cuantiosas sin causa adecuada, gastos ruinosos, autorizan la interdicción" (art. 445 CC).

Claro Solar señala que "pródigo o disipador, es el que desperdicia y consume su hacienda o caudal en gastos inútiles y vanas profusiones, sin orden ni razón, sin fin útil para él ni para la sociedad" 23 . Somarriva entiende que "dentro de la inevitable falta de precisión, si se quiere formular una regla general, puede decirse que son rasgos distintivos de la prodigalidad: el gastar el dinero sin tasa, medida ni control; y el efectuar esos gastos sin fines de lucro; si ellos se hicieren con miras a obtener una utilidad o ganancia, aun cuando los gastos fueren cuantiosos, no significarían disipación" ${ }^{24}$. Fueyo Laneri enseña que dilapidar significa etimológicamente lanzar piedras, "por lo mismo que dilapidación significa gastar dinero como quien lanza piedras a la calle. Este lanzar dinero debe estar representado por un conjunto de actuaciones que resultan armónicas entre sí, y que obedecen a una misma causa, que es una pasión" 25 , de modo que la disipación "Es el resultado de una pasión incontrolada, que lleva a quien la sufre a gastos exagerados en relación con el propio patrimonio, en aras del vicio o de costumbres desarregladas" 26 . Por su parte, Ramos dice que "entendemos por disipador a la persona que gasta su fortuna sin lógica alguna, en forma inmoderada, sin relación a lo que tiene" 27 .

Se exige que se trate de gastos excesivos considerando el patrimonio del afectado (es relativo a los bienes que tenga o de que disponga ${ }^{28}$ ) y que ellos no tengan una justificación razonable: "debe tratarse de gastos que sólo tengan por causa el apego a una vida desordenada, irracional y caprichosa" 29 . No basta un acto aislado, sino que "la ley quiere que se manifieste en el supuesto disipador una mala inclinación, un hábito que se declara, y no una simple falta o varias faltas accidentales y de un momento de extravío" 30 .

La doctrina señala que no es necesario que el disipador sea casado, tenga hijos o herederos forzosos para que proceda la interdicción o que tenga herederos forzosos, como se podría desprender de las personas que pueden demandar la interdicción (art. 443 CC) ${ }^{31}$.

${ }^{23}$ Claro Solar, L., ob. cit., t. V, No 2378 , p. 51.

${ }^{24}$ Somarriva, M., ob. cit., $\mathrm{N}^{\circ} 759$, p. 695.

${ }^{25}$ Fueyo, F., ob. cit., t. III, No 1281 , p. 720. Casi en forma literal repite esta idea Alessandri Besa, A., ob. cit., t. II, $\mathrm{N}^{\circ} 886$, p. 104.

${ }^{26}$ Fueyo, F., ob. cit., t. III, N ${ }^{\circ} 1280$, p. 720.

${ }^{27}$ Ramos, R., ob. cit., $\mathrm{N}^{\circ} 853$, p. 607.

${ }^{28}$ Lyon, A., ob. cit., No 149 , p. 189.

${ }^{29}$ Lyon, A., ob. cit., $\mathrm{N}^{\circ} 149$, p. 189.

${ }^{30}$ Claro Solar, L., ob. cit., t. V, No 2381, p. 53.

${ }^{31}$ Claro Solar, L., ob. cit., t. V, No 2388, p. 60. 


\section{Semejanzas y diferencias}

Hay una cierta semejanza entre los comportamientos del demente y del pródigo de cara a la administración de sus bienes. Ya desde el Derecho Romano se señala que los pródigos, aunque puedan parecer de mente sana y equilibrada, se conducen como locos en lo que respecta a sus bienes (D. 26. 5. $12 \S 2$ ). Claro Solar cita a Demolombe, quien para justificar que se limite el derecho de propiedad del pródigo aduce que "Sin asimilar la prodigalidad a la locura, no hay que caer en la exageración opuesta y sostener que el pródigo tiene el pleno y libre ejercicio de su razón y sobre todo de su voluntad. Al contrario, hay en la prodigalidad una alteración de estas dos facultades que legitima y pide el socorro de la ley" 32 .

Pero no hay completa identidad entre ambas situaciones. Al parecer la enajenación mental incide más directamente en la razón o inteligencia, mientras que la disipación es una debilidad o anomalía de la voluntad: una carencia, no de conocimiento, sino de prudencia, de autocontrol de los impulsos. Por eso, jurídicamente, mientras el demente es incapaz sin necesidad de la interdicción, el disipador sólo lo es si ha sido puesto en entredicho de administrar sus bienes.

El régimen entre el disipador y el demente presenta diferencias. Podemos mencionar las más notables:

\section{$\left.1^{\circ}\right)$ La interdicción produce diferentes efectos}

El demente es considerado incapaz aun cuando no se haya decretado la interdicción (art. 1447 CC), por lo que sus actos anteriores al decreto de interdicción son inválidos si se prueba que los ejecutó o celebró padeciendo la demencia (art. 465 inc. $2^{\circ}$ CC). No sucede lo mismo con el disipador, quien sólo es incapaz, y sus actos pueden ser impugnados de nulidad, desde que ha sido puesto en entredicho de administrar sus bienes, es decir, desde el decreto judicial de interdicción (provisoria o definitiva) (art. 1447 CC). La doctrina ha puesto de relieve esta distinción: "Existe a este respecto una notable diferencia entre el pródigo y el demente: el demente es absolutamente incapaz de obligarse por el solo hecho de estar privado de sus facultades mentales; mientras que el disipador sólo es incapaz, y relativamente, cuando se halla bajo interdicción de administrar lo suyo, según expresamente lo dispone el art. 1447 "33.

\section{$2^{\circ}$ ) La incapacidad es distinta}

El demente tiene incapacidad absoluta, mientras que el interdicto por disipación es sólo incapaz relativo. Esto conlleva que los actos del demente son susceptibles de nulidad absoluta, no producen ni siquiera obligaciones naturales y no admiten cauciones por parte de terceros (arts. 1447 inc. $2^{\circ}$ y 1682 inc. $2^{\circ}$ CC). Los actos del disipador interdicto no siempre son nulos y pueden tener valor en ciertas circunstancias y bajo ciertos respectos determinados por las leyes (art. 1447 inc. $3^{\circ}$ CC), por ejemplo, si son autorizados por su

\footnotetext{
32 Demolombe, t. VIII, n 691, citado por Claro Solar, L., ob. cit., t. V, No 2382, p. 54.

${ }^{33}$ Claro Solar, L., ob. cit., t. V, No 2387 , p. 60.
} 
curador general. Si no se cumplen los requisitos establecidos por las leyes sus actos son nulos, pero sólo de nulidad relativa.

$3^{\circ}$ ) Hay más personas habilitadas para pedir la interdicción del demente que del disipador

En general, las mismas personas que pueden provocar la interdicción del disipador pueden también pedir la del demente, según lo establece el inc. $1^{\circ}$ del art. 459 CC. Es decir, pueden demandarla el cónyuge no separado judicialmente, los consanguíneos hasta en el cuarto grado, el defensor público y, si el incapaz fuere extranjero, el competente funcionario diplomático o consular (arts. 443 y 444 CC). Pero a estas personas, en el caso del demente, se agrega el padre del menor demente que llega a la mayor edad (art. 457 CC), el tutor del demente que llega a la pubertad (art. 458 CC) y el curador del menor adulto al que sobreviene demencia (arts. 458 inc. $2^{\circ}$ y 459 inc. $2^{\circ}$ CC). Además, la acción corresponde al procurador de la ciudad o a cualquier persona del pueblo "si la locura fuere furiosa, o si el loco causare notable incomodidad a los habitantes” (art. 459 inc. $3^{\circ} \mathrm{CC}$ ).

$\left.4^{\circ}\right)$ Las personas llamadas a ejercer la guarda son diferentes

Las personas designadas para la curaduría del disipador son establecidas por la ley y, a falta de ellas, por el juez (la guarda es legítima o dativa: art. 442 inc. $1^{\circ} \mathrm{CC}$ ). Sólo si el padre o madre ejerce la curaduría de un hijo ya declarado disipador, puede nombrar por testamento la persona llamada a sucederle en la guarda (arts. 442 inc. $2^{\circ}$ y 451 CC). En cambio, la guarda del demente puede ser testamentaria, legítima o dativa (art. 456 inc. $2^{\circ}$ CC).

Los llamados por la ley (guarda legítima) a ejercer la curatela son distintos. A la guarda del disipador son llamados en primer lugar los ascendientes, luego los hermanos y finalmente otros colaterales hasta en el cuarto grado (art. 448 CC). En cambio, a la curaduría del demente es llamado en primer lugar el cónyuge, luego sus descendientes, más tarde sus ascendientes, en cuarto lugar los hermanos, y finalmente los colaterales hasta en el cuarto grado.

Como se ve, la ley no considera conveniente otorgar la curaduría legítima del disipador ni al cónyuge ni a los hijos o descendientes. Es más, el marido o mujer ni siquiera puede ser nombrado judicialmente, ya que la ley prohíbe que un cónyuge sea curador del otro declarado disipador (art. 450 CC).

$5^{\circ}$ ) La demencia y la prodigalidad se prueban de distinta manera

La demencia debe ser probada en el juicio de interdicción por informes sobre la vida anterior y la conducta habitual del supuesto demente. Además, de manera obligatoria, el juez debe decretar informes periciales médicos sobre la demencia y su naturaleza: "oirá el dictamen de facultativos de su confianza sobre la existencia y naturaleza de la demencia” (art. 460 CC).

Para la interdicción del pródigo no se requiere dictamen de facultativos y basta que se acrediten hechos repetidos de dilapidación que demuestren una falta total de prudencia (art. 445 CC). 
$6^{\circ}$ El disipador conserva cierta autonomía incluso patrimonial

La ley prevé que, por regla general, el disipador tenga disponible una suma para gastos personales que puede administrar con independencia del curador: "tendrá para sus gastos personales la libre disposición de una suma de dinero, proporcionada a sus facultades, y señalada por el juez" (art. 453 inc. $1^{\circ}$ CC). Sólo "en casos extremos" el juez puede autorizar al curador a negarle esta independencia y a proveer él mismo a la subsistencia del disipador, procurándole los objetos necesarios (es decir, sin darle dinero). Esta independencia no es concedida al demente.

Del mismo modo, la ley le otorga al disipador el derecho para solicitar la intervención del ministerio público cuando estime que los actos del curador "le fueren vejatorios o perjudiciales” (art. 452 CC). Tampoco tiene esta facultad el demente.

$7^{\circ}$ ) El disipador no ve restringida su libertad personal

El Código Civil dispone que "el disipador conservará siempre su libertad” (art. 453 inc. $1^{\circ} \mathrm{CC}$ ). Para el demente, en cambio, la libertad personal es una regla general, pero con excepciones "en los casos en que sea de temer que usando de ella se dañe a sí mismo, o cause peligro o notable incomodidad a otros" (art. 466 inc. $1^{\circ} \mathrm{CC}$ ). Para ser recluido se necesita autorización judicial, salvo que se lo haga momentáneamente y mientras se obtiene dicha autorización (art. 466 inc. $2^{\circ}$ CC) o, al menos, una resolución administrativa emanada de las autoridades de salud (art. 131 Código Sanitario).

$8^{\circ}$ El disipador tiene una mayor autonomía jurídica

El demente tiene una capacidad jurídica mucho más restringida que la del disipador. Así, por ejemplo, el interdicto por demencia no puede ejercer el derecho a sufragio (art. $16 \mathrm{~N}^{\circ} 1$ de la Constitución), no puede otorgar testamento (art. $1005 \mathrm{~N}^{\circ} 3 \mathrm{CC}$ ) ni ser testigo en uno de ellos (art. $1012 \mathrm{~N}^{\circ} 3$ CC) o en un matrimonio (art. $16 \mathrm{~N}^{\circ} 2$ LMC), ni tampoco repudiar el reconocimiento de hijo, sino a través de su curador y con autorización judicial (art. 191 inc. $2^{\circ}$ CC) ni demandar el divorcio sino por medio de su representante legal (art. 58 LMC).

Por otra parte, la demencia (sin interdicción) produce efectos, además de la imposibilidad de otorgar testamento (art. $1005 \mathrm{~N}^{\circ} 4$ CC) y de ser testigo en él (art. $1012 \mathrm{~N}^{\circ} 2$ CC); la privación del derecho a asentir en el matrimonio del hijo (art. 109 inc. $1^{\circ} \mathrm{CC}$ ); la incapacidad para ser guardador (art. $497 \mathrm{~N}^{\circ} 3 \mathrm{CC}$ ); la incapacidad para adquirir por su voluntad la posesión (art. 723 inc. $2^{\circ} \mathrm{CC}$ ) y la incapacidad para contraer matrimonio (art. $5 \mathrm{~N}^{\circ} 3 \mathrm{LMC}$ ).

Ninguna de estas inhabilidades se aplica al disipador interdicto. Incluso en ocasiones la ley expresamente faculta al disipador para actuar por sí mismo: por ejemplo, para repudiar el reconocimiento como hijo (art. 191 inc. $3^{\circ} \mathrm{CC}$ ) o para demandar el divorcio (art. 58 LMC). 


\section{Tendencias en el Derecho comparado y en el Derecho Internacional}

\section{Derecho comparado}

En numerosos ordenamientos se ha procedido a una reforma del sistema de protección de las personas jurídicamente incapaces. Una tendencia es la de sustituir o precisar la expresión "demente" por una alusión a personas con disminución de sus facultades psíquicas. Otra tendencia es la de posibilitar que el juez adecue las limitaciones de la capacidad autónoma del incapaz según el grado de imposibilidad de autodirección que presente.

El Código Civil italiano de 1942 distingue entre personas sujetas a interdicción judicial y personas inhabilitadas. El art. 414 CC dispone que el mayor de edad o menor emancipado "que se encuentren en condiciones de enfermedad mental habitual que los haga incapaces de atender a sus propios intereses, deben ser interdictos". La interdicción lleva por consecuencia la puesta en tutela de la persona. La inhabilitación, en cambio, produce sólo una incapacidad relativa y da paso a una curatela que concede mayor autonomía al sometido a ella. Son sujetos de inhabilitación los enfermos mentales cuyo estado no sea tan grave como para dar lugar a la interdicción, aquellos que por prodigalidad o por abuso habitual de bebidas alcohólicas o de estupefacientes se expongan ellos o expongan a su familia a graves perjuicios económicos (art. 415 inc. $2^{\circ}$ ). La Ley $\mathrm{N}^{\circ} 6$ de 9 de enero de 2004 profundizó la tendencia hacia un mayor respeto a la autonomía de los incapaces, añadiendo un mecanismo menos invasivo de protección: "l'amministrazione di sostegno", que se prevé para "la persona que, por efecto de una enfermedad o bien de una disminución física o psíquica se encuentra en la imposibilidad, aunque sea parcial o temporal, de proveer a sus propios intereses" (art. 404). En tal caso puede ser asistido por un administrador di sostegno nombrado por el juez de su residencia o domicilio. La ley dispuso, además, que la interdicción procederá sólo "cuando ella sea necesaria para asegurar su adecuada protección [la del interdicto]” (art. 414 CC) $)^{34}$.

La reforma argentina se produjo por la Ley $\mathrm{N}^{\circ} 17.711$, de 1968, y siguió muy de cerca las orientaciones del Código Civil italiano. Esta ley mantuvo la denominación de demencia pero la precisó. Así incorporó el art. 141 al Código Civil con el siguiente tenor: "Se declaran incapaces por demencia las personas que por causa de enfermedades mentales no tengan aptitud para dirigir su persona o administrar sus bienes". Junto a los incapaces, la reforma agregó la figura de las personas "inhabilitadas judicialmente”, que quedan sujetas a curatela pero con autonomía para realizar por sí mismos actos de administración (no de disposición por actos entre vivos). Aquí se contempla a "quienes por prodigalidad en los actos de administración y disposición de sus bienes expusieren a su familia a la pérdida del patrimonio" (art. 152 bis $\mathrm{N}^{\circ}$ 3). Pero también a los "disminuidos en sus facultades cuando sin llegar al supuesto previsto en el artículo 141 de este Código, el juez estime que del ejercicio de su

${ }^{34}$ Sobre la reforma italiana y sus objetivos, puede verse a Pérez de Vargas Muñoz, José, "El sistema italiano de protección de las personas privadas de autonomía”, en Revista de Derecho Privado (España), noviembre-diciembre 2010, pp. 3-26. 
plena capacidad pueda resultar presumiblemente daño a su persona o patrimonio" (art. 152 bis $\mathrm{N}^{\circ}$ 3). Asimismo, se considera inhabilitables “a quienes por embriaguez habitual o uso de estupefacientes estén expuestos a otorgar actos jurídicos perjudiciales a su persona o patrimonio" (art. 152 bis $\mathrm{N}^{\circ} 1 \mathrm{CC}$ ).

En Francia, la reforma se produjo por la Ley Nº 68, de 3 de enero de 1968, que distinguió la situación de los menores de edad y las de los mayores que son protegidos por la ley. Entre los protegidos están las personas "cuyas facultades están alteradas por una enfermedad, una deficiencia o debilitamiento debido a la edad" (art. 490 CC), que pueden quedar sujetos a tutela (la más intensa y amplia de las instituciones protectoras) o a la curatela (art. 508 CC). También "puede ser protegido el mayor que, por su prodigalidad, su intemperancia u ociosidad, se expone a caer en la necesidad o compromete el cumplimiento de sus obligaciones familiares" (art. 488 inc. $3^{\circ}$ CC). En este caso sólo procede la curatela (art. 508-1 CC).

La reforma española se produjo por Ley $\mathrm{N}^{\circ} 13$, de 24 de octubre de 1983, que modificó el Código Civil. Se estableció así la tutela para las personas que sean incapacitadas. El art. 200 CC español dice ahora que "son causas de incapacitación las enfermedades o deficiencias persistentes de carácter físico o psíquico que impidan a la persona gobernarse por sí misma”. La reforma mantuvo la figura del pródigo pero sólo como sujeto a curatela (art. $286 \mathrm{~N}^{\circ} 3 \mathrm{CC}$ ), que no tiene otro objeto que la intervención del curador en los actos que los pródigos no puedan realizar por sí mismos (art. 288 CC).

\section{Derecho Internacional}

El Derecho Internacional, a través de declaraciones, tratados multilaterales o convenciones relativas a derechos humanos, ha mostrado una creciente preocupación por la situación de las personas con discapacidad, y entre ellas por las que sufren de una discapacidad mental. Así, la Convención sobre Derechos de las Personas con Discapacidad (aprobada por la Asamblea de las Naciones Unidas el 13 de diciembre de 2006) señala que "Los Estados Partes reafirman que las personas con discapacidad tienen derecho a ser reconocidas en todas partes como personas ante la ley" y que reconocerán que ellas tienen "capacidad jurídica en pie de igualdad con las demás en todos los aspectos de la vida”, si bien "adoptarán las medidas apropiadas para proporcionar acceso al apoyo que puedan necesitar en el ejercicio de su capacidad jurídica" (art. 12, No 1, 2 y 3). Las "medidas de apoyo" al ejercicio de su capacidad deberán contar con "medidas de salvaguardia" para impedir abusos. Concretamente se dispone que "Esas salvaguardias asegurarán que las medidas relativas al ejercicio de la capacidad jurídica respeten los derechos, la voluntad y las preferencias de la persona, que no haya conflicto de intereses ni influencia indebida, que sean proporcionales y adaptadas a las circunstancias de la persona, que se apliquen en el plazo más corto posible y que estén sujetas a exámenes periódicos, competentes, imparciales e independientes por parte de las autoridades o de órganos judiciales. Las salvaguardias serán proporcionales al grado en que dichas medidas afecten a los derechos e intereses de las personas" (art. $12 \mathrm{~N}^{\circ}$ 4). La Convención también dispone que, sin perjuicio de las medidas de apoyo, "los Estados Partes tomarán todas las medidas que sean adecuadas y eficaces para garantizar el derecho en pie de igualdad de las personas con discapacidad a ser propietarios y heredar bienes, controlar sus propios asuntos 
económicos y tener acceso en condiciones de igualdad a préstamos bancarios, hipotecas y otras modalidades de crédito financiero, y asegurarán que las personas con discapacidad no sean privadas de sus bienes de manera arbitraria" (art. $12 \mathrm{~N}^{\circ} 5$ ).

Estas normas no sólo se aplican a los que padecen una discapacidad física, sino también a los discapacitados por enfermedades o anomalías mentales. El Estudio sobre Legislación Chilena y Salud Mental, elaborado por el Departamento de Salud Mental de la Subsecretaría de Salud Pública, y coordinado por María Soledad Cisternas, señala que el art. 12 de la Convención "representa un salto cualitativo en la manera de visualizar la discapacidad, registrándose un cambio de paradigma" y que "Esta disposición es particularmente aplicable a las personas con discapacidad psicosocial, ya que se ocupa de garantizar la capacidad jurídica, principalmente en cuanto a su facultad de ejercicio" 35 .

En el ámbito de la OEA, se aprobó en 1999 la Convención Interamericana para la Eliminación de todas las Formas de Discriminación contra las Personas con Discapacidad (Guatemala, 6 de julio de 1999). Esta convención agrega como elemento caracterizador de la discapacidad física o mental aspectos del entorno o ambiente social: "una deficiencia física, mental o sensorial, ya sea de naturaleza permanente o temporal, que limita la capacidad de ejercer una o más actividades esenciales de la vida diaria, que puede ser causada o agravada por el entorno económico y social" (art. 1).

Además de estos instrumentos internacionales existen los Principios para la protección de los enfermos mentales y el mejoramiento de la atención de la salud mental (Asamblea General de las Naciones Unidas, 17 de diciembre de 1991), que disponen que la determinación de una enfermedad mental debe hacerse con estricta sujeción a las normas médicas aceptadas internacionalmente y no sobre la base de criterios ajenos a la ciencia médica como la condición política, creencia religiosa, los conflictos familiares o la falta de conformidad con valores morales, sociales, culturales o políticos.

Parece apreciarse, así, una tendencia a una mayor armonización entre las medidas de tutela y protección del discapacitado mental con sus derechos fundamentales y su autonomía en la dirección de su persona y negocios, hasta donde ello sea posible. Por eso, se señala que no siempre la sujeción a guarda del discapacitado mental es la mejor solución, y que se trata de "una decisión compleja, y debe ser considerada en el contexto del derecho de toda persona a tener tanto control sobre su propia vida como sea posible"; de modo que "la designación de un curador no implica que la persona pierda todo su poder de decisión, la posibilidad de actuar por sí mismo [sic] en toda circunstancia, ni su dignidad”. La curatela se concibe, de este modo, como un recurso de ultima ratio: "sólo se va a proceder a la designación de un curador -que vele por los intereses de la persona legalmente incapaz- en caso que sea estrictamente necesario, en atención a su estado de trastorno mental severo y a la consecuencia jurídica que debe acarrear, previa constatación mediante un proceso judicial seguido ante un juez imparcial y con intervención de expertos. En todo caso, aun cuando

${ }^{35}$ Subsecretaría de Salud Pública, División de Prevención y Control de Enfermedades, Departamento de Salud Mental, Estudio sobre legislación chilena y salud mental, Gobierno de Chile, Organización Panamericana de la Salud, Santiago, 2008, p. 84. 
se resuelva nombrar un curador, quedará siempre subsistente un grado mayor o menor de autonomía de la persona declarada incapaz para adoptar ciertas decisiones" 36 .

Puede concluirse que tanto el derecho comparado como el derecho internacional coinciden en, por una parte, ampliar el concepto de demencia, y por otra en flexibilizar los instrumentos de protección y graduar la capacidad jurídica del sometido a una guarda por su incapacidad psíquica ${ }^{37}$.

\section{LA EVOLUCIÓN DE LA LEGISLACIÓN CHILENA EN MATERIA DE DISCAPACIDAD MENTAL Y SU REPERCUSIÓN EN LA INTERPRETACIÓN DE LA INTERDiCCIÓN POR DEMENCIA DEL Código Civil}

\section{De la demencia a la discapacidad mental}

Un primer intento de ampliación legal del concepto de "demencia" se ve en el Código Sanitario (Decreto con Fuerza de Ley $N^{\circ} 725$, de 1968), en el que ya no se habla de loco o demente sino de "enfermo mental". Se incluyen expresamente en este concepto los casos de los alcohólicos y de las personas "que presenten estado de dependencia de otras drogas y substancias" (epígrafe del libro VII del Código). Se establece en dicho Código que el Director General de Salud (hoy día el Director del Servicio de Salud) resolverá sobre la observación de los enfermos mentales, de los que presentan dependencias de drogas u otras substancias, de los alcohólicos y de las personas presuntivamente afectadas por estas alteraciones, así como sobre su internación, permanencia y salida de los establecimientos públicos o particulares destinados a ese objeto (art. 130 CS). La internación de las personas puede ser voluntaria, administrativa, judicial o de urgencia (art. $131 \mathrm{CS}$ ).

Esta internación hoy está reglamentada por el Decreto Supremo No 570 , Ministerio de Salud, de 28 de agosto de 1998, publicado en el Diario Oficial el 14 de julio de $2000^{38}$. Esta normativa ya no distingue entre enfermos mentales, alcohólicos y personas con dependencia de drogas y sustancias, sino que habla en general de "personas con enfermedades mentales". Concretamente define el concepto de "pacientes psiquiátricos" como "Las personas que sufren de una enfermedad o trastorno mental y que se encuentren bajo supervisión o tratamiento médico especializado" (art. 6 Nº 1 D. Sup. No 570). Define también "enfermedad o trastorno mental" como "una condición mórbida que sobreviene en una

${ }^{36}$ Estudio sobre legislación chilena y salud mental... cit., p. 85.

${ }^{37}$ Como señala Pérez de Vargas, J., ob. cit., p. 13, con referencia a la reforma italiana de 2004, se intenta sancionar "un verdadero derecho al apoyo", que "obliga a los familiares y a las instituciones a prestar apoyo a quien lo requiera, procurando así potenciar al máximo las posibilidades de autodeterminación del individuo conforme a sus concretas capacidades".

${ }^{38}$ Este decreto derogó el decreto supremo No 68, de 1927, del Ministerio de Higiene, Asistencia y Previsión Social, que aprobó el Reglamento General para la Organización y Atención de los Servicios de Salubridad Mental y Hospitalización y Reclusión de lnsanos, así como el Título VIII del decreto supremo No 161, de 1982, del Ministerio de Salud, que aprobó el Reglamento de Hospitales y Clínicas Privadas (art. 60 D. Sup. 570, de 1998). 
determinada persona, afectando en intensidades variables, el funcionamiento de la mente, el organismo, la personalidad y la interacción social, en forma transitoria o permanente". Se especifica que "Las enfermedades o trastornos mentales serán los contemplados en la Clasificación Internacional de Enfermedades, décima versión, de la Organización Mundial de la Salud, con el nombre de 'Trastornos Mentales y del Comportamiento”. Se contempla que este documento, “con las adecuaciones del caso", será aprobado por resolución del Ministerio de Salud, dictada en uso de sus atribuciones legales técnico-normativas, evaluado periódicamente por un grupo experto, convocado específicamente por el Ministerio para tales efectos (art. $6 \mathrm{~N}^{\circ} 2$ D. Sup. $\mathrm{N}^{\circ} 570$ ). Esta nómina fue aprobada por Resolución No 766 exenta, del Ministro de Salud, de 3 de julio de 2003.

Se prevé una curaduría de bienes provisoria a cargo del director del establecimiento en beneficio del enfermo mental. Así, el Código Sanitario dispone que "los Directores de establecimientos especializados de atención psiquiátrica serán curadores provisorios de los bienes de los enfermos hospitalizados en ellos que carecieren de curador o no estén sometidos a patria potestad o potestad marital, mientras permanezcan internados o no se les designe curador de acuerdo a las normas del derecho común" (art. 133 CS) ${ }^{39}$. El D. Sup. 570 reglamenta esta materia señalando que "En el orden patrimonial los pacientes tendrán derecho a que el Tribunal designe un curador de sus bienes y mientras ello no ocurra, corresponderá al director del establecimiento ejercer la curaduría provisoria, mientras permanezcan internados, a menos que se encuentren sometidos a patria potestad" (art. 32 D. Sup. 570). Se agrega que para ejercer esta curaduría el director no necesita de discernimiento, ni está obligado a rendir fianza o a hacer inventario, y que servirá el cargo gratuitamente. En las actuaciones judiciales y extrajudiciales que deba efectuar en el ejercicio de la curaduría goza de privilegio de pobreza. En todo lo demás se rige por las disposiciones comunes que "acerca de la materia" se contemplan en el Código Civil. Se dispone igualmente que, en el caso de los establecimientos del sector público, el ejercicio de la curaduría podrá ser delegado por el director del establecimiento en un profesional, funcionario de su dependencia, que se encuentre capacitado para ejercerla, sin perjuicio de la responsabilidad que le corresponde de velar por el adecuado ejercicio de esta función por parte del delegado (art. 32 D. Sup. 570).

La Ley $\mathrm{N}^{\mathrm{0}} 20.422$, de 10 de febrero de 2010, que establece normas sobre igualdad de oportunidades e inclusión social de personas con discapacidad, dispone que para sus efectos, "persona con discapacidad es aquella que teniendo una o más deficiencias físicas, mentales, sea por causa psíquica o intelectual, o sensoriales, de carácter temporal o permanente, al interactuar con diversas barreras presentes en el entorno, ve impedida o restringida su participación plena y efectiva en la sociedad, en igualdad de condiciones con las demás" (art. $5^{\circ}$ ).

La discapacidad mental es una de las formas de discapacidad: la producida por deficiencias mentales, sea por causa psíquica o intelectual. Así, se establece en la Ley $\mathrm{N}^{\circ} 18.600$, de 19 de febrero de 1987, según las modificaciones introducidas a ella por

${ }^{39}$ La Ley $\mathrm{N}^{\circ} 19.925$, sobre Expendio y consumo de bebidas alcohólicas, de 19 de enero de 2004, dispone algo similar para la persona que es internada por consumo excesivo de bebidas alcohólicas: "A petición de cualquiera de los miembros de la familia del paciente, podrá nombrársele un curador por el tiempo que dure la hospitalización. Los demás tendrán por curador al director del hospital” (art. 38). 
la Ley $\mathrm{N}^{\mathrm{o}} 19.735$, de 22 de junio de $2001^{40}$. De esta forma, se establece que "se considera persona con discapacidad mental a toda aquella que, como consecuencia de una o más limitaciones síquicas, congénitas o adquiridas, previsiblemente de carácter permanente y con independencia de la causa que las hubiere originado, vea obstaculizada, en a lo menos un tercio, su capacidad educativa, laboral o de interacción social" (art. 2 inc. $1^{\circ}$ Ley N ${ }^{\circ} 18.600$ ). Se agrega que "se entiende disminuida en un tercio la capacidad educativa, laboral o de integración social de la persona cuando, considerando en conjunto su rendimiento en las áreas intelectual, emocional, conductual y relacional, se estime que dicha capacidad es igual o inferior al setenta por ciento de lo esperado para una persona de igual edad y condición social y cultural, medido por un instrumento validado por la Organización Mundial de la Salud y administrado individualmente" (art. 2 inc. $2^{\circ}$ Ley $\left.\mathrm{N}^{\mathrm{o}} 18.600\right)^{41 .}$

La Ley $\mathrm{N}^{\mathrm{0}} 19.954$, de 14 de julio de 2004, incorporó en el art. 4 de la Ley $\mathrm{N}^{\mathrm{o}} 18.600$, una norma que posibilita que el padre o madre de un discapacitado mental inscrito en el Registro Nacional de la Discapacidad solicite al juez que decrete su interdicción definitiva por demencia y le nombre curador al padre o madre que lo tiene bajo su cuidado, sin necesidad de juicio contencioso, sino sólo con el mérito de la certificación vigente de la discapacidad y previa audiencia del discapacitado. Por primera vez se observa una cierta flexibilización de la situación del interdicto por demencia, ya que en este caso se señala que se aplicarán las normas de los arts. 440 y 453 que el Código Civil prevé para la guarda del menor adulto y del disipador, en el sentido de poder otorgarle al pupilo la administración de una parte de sus bienes o de una suma de dinero. Respecto de esta última se dice que "La suma de dinero que se asigne al discapacitado para sus gastos personales podrá ser fijada prudencialmente por el mismo curador, de acuerdo con su grado de discapacidad”. Del mismo modo, se prevé que el interdicto puede celebrar contratos de trabajo con la autorización del curador (art. 4 inc. $2^{\circ}$ Ley $\mathrm{N}^{\circ} 18.600$ ). Si bien podría pensarse que esta norma se aplica a cualquier discapacitado mental, surge de la historia de la ley así como de su texto, que se refiere únicamente a los que fueron declarados discapacitados mentales siendo menores de edad (básicamente, por oligofrenia, retardo mental o síndrome de Down). Se pretendió facilitar a los padres de estos niños que llegan a la mayoría de edad el acceder a la curatela sin las exigencias y los costos emocionales y económicos del juicio ordinario de interdicción ${ }^{42}$.

${ }^{40}$ Originalmente, este cuerpo legal estaba destinado a regular la situación de los "deficientes mentales”, y así reza hasta hoy su título: "Establece normas sobre deficientes mentales", pero este no concuerda con la ampliación de la regulación efectuada por la Ley $\mathrm{N}^{\circ} 19.735$, de 2001. También quedó desfasado su reglamento, aprobado por Decreto Supremo No 48, Ministerio del Trabajo, de 7 de mayo de 1993, publicado el 13 de septiembre de 1993, que se refiere también al concepto de "deficiencia mental".

${ }^{41}$ A esta evolución legislativa debe añadirse también el Código Procesal Penal, que no habla de "locura o demencia" (como sigue haciéndolo el Código Penal en su no modificado art. 10), sino de enajenación mental (arts. 458 y ss. del Código Procesal Penal). Asimismo, la Nueva Ley de Matrimonio Civil ya no califica como inhábiles para casarse a "los dementes", sino a "los que se hallaren privados del uso de la razón", a lo que se añade la incapacidad para formar la comunidad de vida matrimonial "por un trastorno o anomalía psíquica" (art. 5 No 3 LMC).

42 Por eso la disposición se centra en los padres, y sólo por ausencia o impedimento de ellos, habilita a los parientes más cercanos. En la moción de los senadores Silva, Ávila, Bombal, Parra y Viera Gallo que dio lugar a la reforma, se apunta a esta necesidad: "el Código Civil exige cumplida la mayoría de edad someter al 
Otra forma de curaduría, esta vez otorgada sin intervención judicial, es la que contempla el art. 18 bis de la Ley $\mathrm{N}^{\circ}$ 18.600. Se señala que, si cumplen ciertos requisitos que se establecen, las personas naturales o jurídicas que se encuentren inscritas en el Registro Nacional de Discapacidad y que tengan a su cargo personas con discapacidad mental, cualquiera sea su edad, serán "curadores provisorios de los bienes de éstos [sic], por el solo ministerio de la ley" (art. 18 bis inc. $1^{\circ}$ Ley $\mathrm{N}^{\circ}$ 18.600). Si bien no resulta del todo clara la significación de esta curaduría provisoria "de bienes", es evidente que está vinculada con la normativa del Código Civil sobre guardas, como lo pone de manifiesto la misma norma, al hacer aplicables las disposiciones de este Código sobre incapacidades y derechos y obligaciones de los curadores. La Contraloría General de la República ha señalado que dentro de las personas naturales que menciona la disposición pueden estar los parientes del discapacitado: "Como se puede apreciar, la norma citada no establece limitaciones en cuanto a quienes pueden inscribirse como personas naturales en el mencionado Registro, por lo que debe entenderse que dicha expresión también comprende a los parientes del discapacitado mental" (Dictamen No 1449, de 14 de enero de 2003).

La ley señala, además, que "La curaduría provisoria durará mientras permanezcan bajo la dependencia y cuidado de las personas inscritas en el Registro aludido y no se les designe curador de conformidad con las normas del Código Civil” (art. 18 bis inc. $3^{\circ}$ Ley N ${ }^{\circ} 18.600$ ).

Es lógico pensar que la curatela a la que se refiere esta norma es la que corresponde al demente.

\section{Repercusión sobre el concepto de demencia del Código Civil}

Resulta notorio que el concepto de demencia del Código Civil, que la doctrina y la jurisprudencia siempre han entendido de manera amplia y abierta a todo lo que la ciencia médica indique como perturbación o deficiencia mental, debe ser hoy día interpretado conforme al concepto de "discapacidad mental", al que se refieren las Leyes $\mathrm{N}^{\circ} 20.422$ y $\mathrm{N}^{\circ} 18.600$.

Aunque las referidas leyes tienden a establecer beneficios para la protección y la inclusión social de los discapacitados y no a regular la cuestión de su capacidad legal y

discapacitado a las reglas de un juicio para comprobar o acreditar a[l]go que todos sabemos: es discapacitado mental, y que regularmente será un estado de carácter permanente. He aquí el principal conflicto que tienen [sic] la familia de discapacitados: Exponerse ante un juicio que no es tal, con el objeto de acreditar que su hijo o familiar es 'demente'”. Cuando la Comisión de Constitución del Senado informó el proyecto se dejó constancia de "la necesidad de reformular las normas sobre incapacidad mental de las personas, que no responden hoy a los avances de la medicina, a la consideración social más positiva de las personas discapacitadas y a las necesidades del desarrollo de la personalidad de éstas" y de que "Es evidente que, dentro de este tema general, requieren más atención no sólo las llamadas deficiencias mentales, sino también las perturbaciones del juicio, moderadas o más severas, que afectan a los adultos mayores", pero se concluyó que "Esta tarea, sin embargo, debería ser abordada mediante un trabajo interdisciplinario, que excede los marcos del proyecto de ley" (Informe de 13 de agosto de 2002, Boletín No 2.972-07). Por su parte, la Comisión de Constitución de la Cámara de Diputados estimó igualmente que "la norma propuesta, si bien no soluciona en forma omnicomprensiva el tema de la discapacidad mental, al menos permite dar solución a un problema puntual que aqueja a un gran número de personas" (Informe de 19 de mayo de 2004, Boletín No 2.972-07). 
su representación, resulta claro que asocian el concepto de discapacidad mental con las disposiciones del Código Civil sobre incapaces por demencia, como lo prueba la curaduría provisoria prevista en el art. 18 bis de la Ley $\mathrm{N}^{\circ} 18.600$ y la interdicción por demencia no contenciosa contemplada en el art. 4 de la misma ley.

En este sentido, lo que la doctrina ya había afirmado para la ebriedad podría ser aplicado a la adicción a las drogas. Según Claro Solar, como ya vimos, si la embriaguez lleva a un desorden mental que ocasiona "necesidad irresistible de beber, que puede complicarse con accesos más o menos frecuentes de delirio... y llegando a constituir esta embriaguez o alcoholismo un estado habitual, justificaría, sin duda, la interdicción por demencia" 43 .

Debe destacarse, sin embargo, que no bastará que una persona sea considerada, en conformidad con estas leyes, como discapacitada mental para que se le declare interdicta por demencia y se le ponga bajo curaduría. Será necesario que se acredite, por dictamen de expertos o facultativos médicos, que, por el grado o naturaleza de la discapacidad, el afectado no pueda dirigirse a sí mismo o administrar competentemente sus negocios, que es el requisito fundamental para que pueda procederse a designar tutor o curador según la definición contenida en el art. 338 del Código Civil.

Así, por ejemplo, como sostiene Alberto Lyon, "un sujeto que padece una enfermedad mental que le provoca en forma periódica estados de enajenación que le privan de la facultad de discernir no puede ser privado de la administración de sus bienes, pues el estado de demencia no constituye su forma habitual de ser o estar. Los problemas prácticos que se presentan deberán solucionarse por otra vía (nombramiento de mandatario, etc.); pero no puede recurrirse a la interdicción y al posterior nombramiento de curadores" 44 .

No obstante, también es cierto que si la enfermedad mental, aunque sólo produzca florecimientos intermitentes, por su frecuencia, imprevisibilidad, duración y otros factores concurrentes, da lugar a la valoración normativa de que la persona no cuenta con la aptitud adecuada para autogobernarse o dirigirse a sí misma, será procedente la interdicción por demencia y el nombramiento de un curador general ${ }^{45}$. En tales casos, conviene pensar que en los períodos de remisión de la enfermedad el sujeto se encuentra en intervalo lúcido, con lo que sus actos podrían tener algún efecto, según lo disponga la legislación. Es cierto que existe la norma del art. 465 del Código Civil que dispone que los actos y contratos del demente posteriores al decreto de interdicción serán nulos aunque se alegue haberse ejecutado o celebrado en un intervalo lúcido, pero esta norma debe interpretarse restrictivamente y como aplicable únicamente a los actos de disposición y gestión patrimonial, como ya lo precisaba Claro Solar: “¿A qué actos y contratos del demente ha querido, pues, referirse el

${ }^{43}$ Claro Solar, L., ob. cit., t. V, N 2426 , p. 108.

${ }^{44}$ Lyon, A., ob. cit., $\mathrm{N}^{\circ} 140$, p. 181.

${ }^{45}$ En España, se ha discutido el problema de las llamadas enfermedades mentales de carácter cíclico. Según Heredia Puente, M. y Fábrega Ruiz, C., Protección legal de incapaces, Colex, Madrid, 1998, p. 28, en caso de duda habría que decantarse en contra de la incapacitación, pero "en los estadios más graves y avanzados -cuando la intensidad y la periodicidad de las fases críticas afecte al autogobierno de la persona- habrá que buscar mecanismos de protección adecuados a cada caso", entre los que sugieren la incapacitación permanente aunque de menor intensidad por medio de una curatela limitada a la esfera patrimonial. 
art. 465? Para fijar su alcance hay que tener presente el objeto mismo de la interdicción. Dice la ley que 'el adulto que se halla en estado habitual de demencia, deberá ser privado de la administración de sus bienes, aunque tenga intervalos lúcidos’. La interdicción es, por lo tanto, la privación de la administración de los bienes... Por consiguiente, al referirse a 'los actos o contratos del demente' la ley ha entendido indicar todos aquellos que miran a la administración y disposición de los bienes, a todos los actos pecuniarios o patrimoniales" ${ }^{46}$.

La interdicción por demencia, por tanto, no siempre trae la incapacidad para realizar actuaciones con relevancia jurídica, salvo que la ley establezca la incapacidad para el "interdicto por demencia" (por ejemplo, para suspender el derecho de sufragio o para testar). Si lo hace sólo para el demente sin referirse a la interdicción se entiende que comprende a los que no hayan sido declarados interdictos y también a los interdictos, pero siempre que se pruebe que no actuaron en un período de lucidez (por ejemplo, para el asentimiento del matrimonio de un hijo o para adquirir la posesión por voluntad propia).

Por ello, tampoco son considerados incapaces de delito o cuasidelito los interdictos por demencia, ya que el art. 2319 CC no se refiere a los “interdictos" sino a los dementes, y en este caso se debe mantener el sentido restringido de demencia como pérdida o privación actual de la razón. En consecuencia, si un interdicto por demencia actúa en intervalo lúcido responderá por delito o cuasidelito civil ${ }^{47}$.

La jurisprudencia aplica este criterio a la eximente de responsabilidad penal prevista en el art. $10 \mathrm{~N}^{\circ} 1$ del Código Penal, que exonera de responsabilidad al loco o demente salvo que haya obrado en un intervalo lúcido. No basta una discapacidad o trastorno mental, si el sujeto al momento de actuar tenía la capacidad de autodeterminación y no se abstuvo de la conducta delictiva, aunque sí puede constituir la eximente incompleta del art. $11 \mathrm{~N}^{\circ} 1^{48}$.

En suma, la expresión "demencia" en el contexto de las normas relativas a la interdicción se debe entender en el sentido abierto, no técnico y amplio propiciado desde antiguo por la doctrina, y hoy configurado dentro del concepto genérico de discapacidad mental. Pero ello sólo como el primer elemento, al que debe añadirse la habitualidad y la incapacidad de dirigirse a sí mismo que aconseja la sujeción del afectado a una guarda intensa como la curatela del demente.

La palabra "demencia" fuera del contexto de la incapacitación debe ser entendida en el concepto más preciso de privación actual de la razón. Por ello, en estos casos, no se considerará demente al discapacitado mental sino únicamente a aquel que en el momento de realizar la conducta descrita por la ley estaba privado de razón o del entendimiento necesario para determinar sus actos. Si la persona está ya interdicta por demencia, procede (tanto en su favor

${ }^{46}$ Claro Solar, L., ob. cit., t. II, No 2450, p. 139.

${ }^{47}$ Claro Solar, L., ob. cit., t. II, No 2448, p. 133.

${ }^{48}$ Así, C. San Miguel, $1^{\circ}$ de abril de 2002, Gaceta Jurídica No 262, p. 155; C. Santiago, 18 de abril de 2006, rol Corte N N13-2006, RUC N $^{\circ}$ 0500242938-3. Igualmente, se ha dicho que si el imputado presenta un tipo de anormalidad psíquica, caracterizada por un insuficiente desarrollo de las facultades intelectuales, no siendo capaz de comprender lo injusto de su actuar y de autodeterminarse con arreglo a dicha comprensión, concurre la eximente del art. $10 \mathrm{~N}^{\circ} 1$ del Código Penal, sin que a ello obste el hecho de que la persona no estuviere inscrita en el Registro Nacional de la Discapacidad (Tribunal Penal Oral de Viña del Mar, 26 de noviembre de 2005, RUC No $0500107962-1$, cons. $15^{\circ}$ ). 
como en su contra) que se alegue que actuó sin estar afectado actualmente por la discapacidad mental que padece y que procedió en intervalo o período lúcido, salvo que se trate de actos de disposición o administración patrimonial a los que se aplica la norma del art. 465 del Código Civil que prohíbe la alegación de intervalo lúcido para actos posteriores a la interdicción.

Tampoco procederá la alegación de intervalo lúcido cuando la ley no hable de demente sino de interdicto por demencia. En esos casos, bastará la prueba de la interdicción para establecer la inhabilidad, invalidez o consecuencia legal que proceda.

\section{LA INTERDICCIÓN POR DISIPACIÓN}

Para que haya interdicción por disipación, según el art. 445 inc. $1^{\circ} \mathrm{CC}$, se necesita probar:

$1^{\circ}$ ) Que el afectado ha incurrido en hechos de dilapidación. La ley no define lo que considera dilapidación pero pone ejemplos: juego habitual en que se arriesgan porciones considerables del patrimonio, donaciones cuantiosas sin causa adecuada, gastos ruinosos (art. 445 inc. $2^{\circ} \mathrm{CC}$ ). Como ya hemos visto, la doctrina señala que esta mención es meramente ilustrativa y no agota las posibilidades de otras actuaciones que demuestren la disipación.

$2^{\circ}$ ) Que esos hechos hayan sido repetidos.

$3^{\circ}$ ) Que ellos manifiesten una falta total de prudencia.

Queda claro que no puede declararse la prodigalidad sobre la base de un riesgo o peligro de que se incurra en actos de dilapidación, reiterados o no, si estos no han tenido lugar. Pero otra cosa es que deba esperarse a que el patrimonio esté mermado significativamente. Basta que haya un riesgo serio y previsible de que se podrá causar dicho menoscabo por la conducta irresponsable y malgastadora del afectado.

En este sentido, puede compartirse lo señalado por el jurista español Federico de Castro y Bravo, cuando señala que es preciso que la conducta del demandado como pródigo "se revele verdaderamente peligrosa para el patrimonio. $\mathrm{O}$ sea, que se requiere que haya unos bienes a los que poner en peligro y que este peligro sea objetivo, revelado por actos inequívocos. Peligro que se refiere no a la proximidad de la ruina, a la pobreza propia o a la destrucción rápida de un capital, sino al carácter de la conducta misma, indiciario de la probabilidad de esos resultados en un futuro previsible" ${ }^{49}$.

En Argentina, incluso contra el texto del art. 152 bis del Código Civil que autoriza la inhabilitación por prodigalidad cuando se hubiere dilapidado "parte importante" de los bienes, la doctrina concluye que "si bien la norma exige una pérdida efectiva del patrimonio, parece razonable extender su aplicación a los supuestos de peligro inminente aun no consumado" ${ }^{50}$.

49 De Castro y Bravo, F., Derecho Civil de España, Instituto de Estudios Políticos, Madrid, 1952; reimp. Thomson Civitas, Madrid, 2008, t. II, p. 338.

${ }^{50}$ Borda, A., "La capacidad", en La persona humana, Guillermo A. Borda (dir.), La ley, Buenos Aires, 2001 , p. 185 . 
Entre nosotros, Claro Solar ha dicho que no es necesario que se haya producido ya una merma importante del patrimonio, "basta que la conducta de éste manifieste una falta total de prudencia para decretar la interdicción, precisamente antes que el disipador haya perdido la mayor parte de su patrimonio" ${ }^{1}$. Existe un antecedente histórico que avala esta interpretación: en el Proyecto de 1853 se establecía expresamente que "en todo caso deberá probarse que por estas causas se ha producido efectivamente una disminución considerable en el patrimonio del supuesto dilapidador" (art. 512). Esta norma fue eliminada posteriormente, de lo que se sigue que no es necesario que se allegue esta prueba en el juicio de interdicción.

Otra duda que puede plantearse es si los hechos de dilapidación han tenido como consecuencia la pérdida de todos los bienes relevantes del patrimonio del disipador, éste no podría ya ser interdicto puesto que no hay patrimonio cuya administración se deba proteger o tutelar. Pensamos que esto no es así: por una parte, nada impide que el disipador no pueda adquirir nuevos bienes, ya sea por su trabajo, subsidios sociales o liberalidades de terceros, y que, sin el decreto de interdicción, y dada su inclinación al despilfarro, nuevamente volverá a derrochar. Por otra parte, uno de los actos más ruinosos que puede realizar una persona es el de contraer empréstitos que no podrá luego pagar, y que, para evitar el embargo de sus pocos bienes de uso doméstico y personal, deberán sus familiares más cercanos allanarse a satisfacer. Impedir estos actos irresponsables que tienen por objeto no la disminución del activo sino el incremento del pasivo patrimonial, es una parte de las funciones de la interdicción por disipación.

No existe mayor jurisprudencia sobre casos de dilapidación. Puede mencionarse una sentencia de la Corte Suprema de 11 de noviembre de 1991, Gaceta Jurídica No 137, p. 66, que acogió un recurso de amparo deducido por una persona declarada interdicta por disipación que había sido privada de libertad por el delito de giro doloso de cheques. La Corte señaló que "girado el cheque por un disipador declarado en interdicción, con el agregado de los requisitos legales de publicidad, el acto de girar el cheque adolece de nulidad y por tanto carece de valor legal" (cons. $5^{\circ}$ ). Además, añadió que "resulta evidente que el interdicto, atendida la prohibición que le afecta para disponer de sus bienes, no puede ser compelido válidamente para efectuar el depósito" que ordena la ley dentro de tercero día desde la notificación del protesto (cons. $15^{\circ}$ ).

El Tribunal consideró también que si se daba eficacia al giro del cheque por parte del interdicto se estaría vulnerando la finalidad de la interdicción por disipación: "que mayor realce adquiere el señalado vicio frustrante si atendemos a que el acto aquí analizado es precisamente un pago, vale decir, un acto que consiste esencialmente en la transferencia de dinero, evento considerado incontestablemente como de relevante mérito en la medida cautelar que se dictó en favor del incapaz para cuidar sus intereses” (cons. $7^{\circ}$ ). Por ello, "cualquier ligereza o superficialidad en el juzgamiento de un caso como el de la especie, nos conduciría fatalmente a eventuales aprovechamientos de terceros para obtener pagos indebidos o reprochables de quienes carecen de discernimiento suficiente precisamente para medir y ponderar sus desembolsos" (cons. $9^{\circ}$ ).

\footnotetext{
${ }^{51}$ Claro Solar, L., ob. cit., t. V, No 2381, p. 53.
} 


\section{CONCURRENCIA EN UNA SOLA PERSONA DEL RÉGIMEN DE INTERDICCIÓN DE LA DEMENCIA Y DE LA DISIPACIÓN}

\section{Casos en los que no hay concurrencia}

Es claro que existen casos en los que no se da la posibilidad de concurrencia entre el régimen de interdicción de la demencia y el de la prodigalidad. Así sucede:

$1^{\circ}$ Si la persona afectada padece de una discapacidad mental, pero su trastorno mental no le hace incurrir en actos de disipación patrimonial (por ejemplo, si su trastorno mental es más bien el de alguien obsesivamente conservador y ahorrativo). En este caso, procederá, si se cumplen los requisitos propios, la interdicción por demencia, pero no por disipación.

$2^{\circ}$ Si la persona incurre en actos repetidos de dilapidación, pero no por causa de una discapacidad mental, sino únicamente por desórdenes morales, por filantropía imprudente o por querer perjudicar a sus familiares. En este supuesto, corresponderá la interdicción por prodigalidad pero no por demencia.

El problema se presenta cuando respecto de una misma persona se dan las causas que autorizan tanto la interdicción por demencia como la interdicción por prodigalidad. Es decir, la persona padece de una discapacidad mental, y es ésta la que lo lleva a incurrir en gastos ruinosos y sin justificación razonable. ¿Qué sucede en tal caso?

\section{Procedencia de la concurrencia}

\section{a) Posición negativa}

Hay quienes piensan que no es posible la confluencia normativa entre el régimen de la demencia y el de la prodigalidad. Se basan en que la prodigalidad sólo puede aplicarse cuando no existen trastornos mentales que la motiven. En este sentido, el jurista español Federico de Castro se opone a la caracterización de la prodigalidad sobre la base de una concepción subjetiva que, tomando como base los textos romanos que asimilaban el pródigo al loco, consideran que el disipador es víctima también de un desarreglo mental, incluso de una manía: la manía de gastar. En su visión, en la prodigalidad debe tenerse en cuenta una conducta creadora de un peligro para el patrimonio que resulta socialmente condenable por poner en riesgo la situación económica de la familia más cercana ${ }^{52}$.

Esta idea es recogida con la nueva legislación española por el profesor Manuel Albaladejo, quien escribe que "no es la prodigalidad una enfermedad, sino una conducta económicamente desarreglada", por lo que "no provoca una limitación de la capacidad en interés del que la sufre, sino en el de sus familiares" 53 .

\footnotetext{
52 De Castro, F., ob. cit., t. II, pp. 336-341.

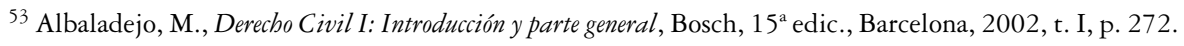


Lo mismo se considera en Francia. Según Gilles Goubeaux si la ley toma en cuenta la prodigalidad, ella no tiene que estar vinculada a ningún tipo de alteración mental: "sin duda se trata de comportamientos que pueden considerarse anormales. Pero ellos son considerados por sí mismos y no como reveladores de una enfermedad o debilidad del espíritu" 54 .

\section{b) Posición de la concurrencia necesaria}

Según esta segunda teoría la concurrencia es inevitable, toda vez que la disipación, con los avances de la ciencia médica, no puede ser considerada sino como una perturbación o alteración psíquica o mental. En la doctrina italiana se señala, en este sentido: "La llamada prodigalidad ha sido entendida por la jurisprudencia y la doctrina prevalecientes como una anomalía psíquica que se manifiesta con una tendencia irreprimible a 'gastar de modo desordenado y desmesurado', derrochando o disipando el propio capital. En otro tiempo, era considerada como algo distinto de la enfermedad mental... Hoy, en virtud de una nueva configuración, amplia y articulada, de las dolencias mentales (en cuya disciplina se ha pasado, conforme se anotó, de una concepción 'custodialista' a una actitud terapéutica...), esa distinción ha perdido su significado originario, como quiera que incluso los pródigos se pueden definir... como "perturbados psíquicos"”55.

De esta forma, siempre que hay prodigalidad hay también enfermedad mental, si bien especificada por la consecuencia de desarrollar un comportamiento irresponsable desde el punto de vista del cuidado de los propios bienes.

\section{c) Posición de la concurrencia eventual}

Una tercera posición es aquella que observa que en la prodigalidad pueden comprenderse dos situaciones personales: la del pródigo "puro" en el que puede haber un desorden conductual pero no morboso ni constitutivo de una enfermedad o patología mental y la del pródigo que padece ya sea una alienación o a lo menos una anormalidad fronteriza de carácter mental. En este sentido parecen inclinarse los argentinos Mattera y Noya ${ }^{56}$.

Siguiendo esta posición, la concurrencia con la demencia sólo se dará en los casos en los que la prodigalidad sea el resultado de una patología o alteración psíquica, pero no cuando la persona sea considerada un "pródigo puro", cuya irresponsabilidad patrimonial no tiene sus causas en una anormalidad o trastorno psíquico.

${ }^{54}$ Goubeaux, G., Les personnes, en Traité de Droit Civil, Jacques Ghestin dir., L.G.D.J., Paris, 1989, $\mathrm{N}^{\circ} 695$, p. 567.

${ }^{55}$ Breccia, U.; Bigliazzi, L.; Natoli, U.; Busnelli, F., Derecho Civil: Tomo I volumen I: Normas, sujetos y relación jurídica, trad. Fernando Hinostrosa, Universidad Externado de Colombia, Bogotá, 1992, pp. 151-152.

${ }^{56}$ Mattera, M. y Noya, G., "Los inhabilitados", en La persona humana, Guillermo A. Borda (dir.), La ley, Buenos Aires, 2001, p. 241, siguiendo a José W. Tobías. 


\section{Soluciones ante la concurrencia}

Admitida la posibilidad de concurrencia de regímenes, deben analizarse las posibles soluciones para determinar qué normativa debe ser la aplicable. Si se sostiene que la concurrencia es necesaria, la única manera de mantener la normativa propia de la prodigalidad es hacer prevalecer este régimen por sobre el de la demencia, por aplicación del principio de especialidad. De esta manera, si bien la enfermedad mental que afecta al pródigo podría dar lugar a la interdicción por demencia, por existir una normativa específica que cubre totalmente el tipo de anomalía de que se trata: la disipación patrimonial, estas normas deben prevalecer. El sujeto debe ser tratado como un pródigo y no como un demente. Se aplicarán todas las normas relativas a este régimen, en cuanto a las personas autorizadas a pedir la interdicción, prueba de ella, llamados a la curaduría, efectos de la interdicción, etc.

Si la concurrencia es sólo eventual y no necesaria, podrían caber dos alternativas. Seguir la teoría anterior para el caso en que la prodigalidad no es pura, sino producto de una alteración psíquica, o estimar que en este caso no es aplicable el régimen de la prodigalidad sino el de la demencia, que tendría aplicación a todos los casos de anormalidades psicopatológicas, cualquiera fuera la forma en que se manifiesten. En cambio, las normas de prodigalidad sólo podrían aplicarse cuando la persona afectada incurre en la conducta de disipación sin que ella sea el resultado de un desequilibrio psíquico morboso ${ }^{57}$.

\section{Nuestra opinión}

Teniendo en cuenta la normativa de nuestro Código Civil, y la caracterización de los regímenes propios de la prodigalidad y la demencia, así como la reinterpretación que cabe efectuar a la demencia sobre la base de los avances de la psiquiatría moderna y las normativas sobre discapacidad mental, debemos considerar que es posible la concurrencia en un mismo sujeto de las características propias de la discapacidad mental (propias de la interdicción por demencia) y de la prodigalidad (propias de la interdicción por disipación).

Se trataría, en todo caso, de concurrencia eventual y no necesaria, ya que no cabe excluir que existan supuestos de prodigalidad que no obedezcan a una discapacidad mental y que sean el resultado de malos hábitos o intenciones caprichosas, dolosas o irresponsables del afectado. Pensamos, en consecuencia, que pueden existir pródigos puros, en los que no se produce ninguna confluencia normativa con el régimen propio de los dementes.

${ }^{57}$ Es lo que parece sostener la doctrina argentina, pero con la particularidad de que el afectado sería igualmente "inhabilitado", y no incapacitado como demente, por la causal del art. 152 bis inc. $2^{\circ}$ del Código Civil: "disminución en sus facultades mentales". De esta forma, se señala que si bien la omisión de una pericia médica no constituye una causal de nulidad del proceso de prodigalidad, es muy conveniente decretarla, "por cuanto permitiría determinar si se trata de una prodigalidad sintomática (encuadrable en el inc. $2^{\circ}$ ) o esencial, en cuyo caso habrá de producirse la exhaustiva prueba que requiere el inc. $3^{\circ}$ [del art. 152 bis CC]" (Mattera, M. y Noya, G., ob. cit., p. 241, siguiendo a José W. Tobías). En Francia, la doctrina afirma que es posible que un requerimiento de prodigalidad pueda devenir en el curso del proceso en una declaración de incapacidad por alteración no grave de las facultades mentales siempre que se haya acompañado el correspondiente dictamen médico: cfr. Goubeaux, G., ob. cit., p. 567. 
En los casos de prodigalidad coincidente con una patología o discapacidad mental, no parece que necesariamente deba aplicarse la normativa propia de la demencia y no de la prodigalidad. En efecto, si bien podría argumentarse que el principio de especialidad juega en favor del régimen de la demencia, ya que esta se aplicaría a todas las personas que padezcan de una enfermedad psíquica, la verdad es que lo mismo podría aducirse, también sobre la base de la especialidad, pero para que prevalezca la normativa sobre prodigalidad: la ley querría que todos los que incurran en disipación de sus bienes, cualquiera sea su causa, incluidos los desequilibrios o alteraciones mentales, deben ser tratados como pródigos y no como dementes.

De esta forma, el examen del conflicto de normas sobre la base únicamente de sus textos y en una perspectiva de solución de "todo o nada", no parece ofrecer una solución satisfactoria.

Es necesario realizar un análisis de los regímenes sobre la base de sus finalidades, y a la luz de las tendencias del derecho comparado e internacional que ponen el acento en el respeto de los derechos fundamentales de los incapaces y en la función tutelar o protectora de los regímenes que se diseñan, así como su adaptabilidad a los caracteres personales del incapaz $^{58}$.

Las normas de la interdicción por demencia tienen por finalidad proteger a quienes necesitan un régimen tutelar de gran intensidad intervencionista, porque el padecimiento mental de la persona le impide gobernarse a sí misma en todo tipo de asuntos y no sólo en los patrimoniales. De esta manera, su curador debe sustituirlo en toda actuación jurídica que sea relevante y hasta puede ver restringida su libertad personal. En cambio, la interdicción por prodigalidad tiene por finalidad proteger a la persona, y a su familia, de una administración irresponsable de su patrimonio, pero no se interviene en su libertad personal, e incluso puede gozar de una cierta independencia económica. No necesita actuar representado, sino que basta que sea autorizado para sus actos patrimoniales. Puede realizar autónomamente actos tan importantes como el matrimonio, el reconocimiento de un hijo o el testamento.

Debe anotarse la diferencia que hace el art. 338 del Código Civil, al definir las tutelas y las curadurías, como cargos a favor de "aquellos que no pueden dirigirse a sí mismos o administrar competentemente sus negocios”. Adviértase la preposición disyuntiva "o" que parece aludir a dos tipos de protegidos por las guardas: los que no pueden dirigirse a sí mismos (y por ende tampoco sus negocios) y los que, si bien pueden dirigirse a sí mismos, no pueden administrar con competencia sus propios negocios. Entre los primeros están los dementes; entre los segundos deben figurar los pródigos.

${ }^{58}$ La Ley No 20.422, de 2010, que estableció el nuevo estatuto de las personas discapacitadas, se orienta en esta tendencia. Así se dispone que "El Estado adoptará las medidas necesarias para asegurar a las mujeres con discapacidad y a las personas con discapacidad mental, sea por causa psíquica o intelectual, el pleno goce y ejercicio de sus derechos en condiciones de igualdad con las demás..." (art. 9, énfasis añadido), y también que "El Estado promoverá la autonomía personal y la atención a las personas en situación de dependencia a través de prestaciones o servicios de apoyo..." y que "la atención de las personas con discapacidad en situación de dependencia, deberá facilitar una existencia autónoma en su medio habitual y proporcionar un trato digno en todos los ámbitos de su vida personal, familiar y social” (art. 12). 
Si esto es así, el juez sólo puede declarar interdicta por demencia a la persona que padece una discapacidad mental si ella tiene la gravedad suficiente para impedir que el incapaz pueda dirigirse a sí mismo ${ }^{59}$. Si la discapacidad mental es de tal naturaleza que puede limitar las facultades del sujeto para administrar su propio patrimonio, pero no lo inhabilita para gobernarse como persona, procederá la interdicción por prodigalidad (si se comprueba la disipación).

Por lo tanto, en el caso en que en un mismo individuo concurran las causales para declarar la interdicción por demencia y por prodigalidad, el juez deberá juzgar el régimen aplicable sobre la base de cuál es aquel que se adecua más a las necesidades de protección del afectado y sus intereses personales y patrimoniales. Si el desorden mental es de tal gravedad o naturaleza que permite aconsejar que sea declarado absolutamente incapaz por no poder gobernarse a sí mismo en todo orden de cosas, decretará la interdicción por demencia. En caso contrario, debiera aplicar el régimen menos gravoso y más flexible de la interdicción por prodigalidad.

\section{Planteamiento procesal de la concurrencia}

Hemos de decir que después de la Ley No 20.286, de 15 de septiembre de 2008, de reforma a la Ley $\mathrm{N}^{\circ} 19.968$ sobre Tribunales de Familia, las causas de interdicción son de competencia de los tribunales ordinarios con jurisdicción en lo civil y se aplica a ellas el procedimiento del juicio ordinario (art. 3 del Código de Procedimiento Civil).

Resta saber cómo debería plantear el demandante el caso si concurren en el afectado las situaciones para ser declarado interdicto por demencia y por disipación.

Nos parece que en tal evento estamos frente a un concurso no sólo de normas sino de acciones, en cuanto la calificación jurídica de los hechos incluye la causa de pedir de la acción. Es decir, no hay una única acción de interdicción, sino que es diversa la acción de interdicción por demencia de la acción de interdicción por disipación (sus titulares son diversos, sus fundamentos son distintos, sus efectos varían, etc.).

Ante la concurrencia de acciones se plantea el problema de su acumulación procesal. Una primera forma de acumulación sería la alternativa. Es decir, que el demandante interpusiera en la demanda tanto la acción de interdicción por demencia como la acción de interdicción por disipación pero dejando al juez la decisión de cuál es la que mejor procede en el caso. Se demandaría la interdicción por demencia o la interdicción por disipación. Esta parece ser la mejor forma de plantear el caso ya que en definitiva será la prueba y la

${ }^{59}$ Corresponde a la exigencia que hace el art. 200 del Código Civil español que la enfermedad o debilidad mental impida a la persona gobernarse por sí misma. Se trata de una calificación jurídica de los conceptos médicos: "hay un intento de poner correctivos jurídicos a la caracterización estrictamente psicopatológica de la incapacidad de obrar, con la finalidad última, según creemos, de privar a los profesionales de la medicina de la 'última palabra' en materia de incapacitación (o de incapacidad natural), y confiar dicha función 'definitoria' o 'constitutiva' (de la protección institucional) a los órganos jurisdiccionales, que actuarán con criterio 'legal' sobre la información aportada y/o requerida a iniciativa suya” (Ramos Chaparro, E., La persona y su capacidad civil, Tecnos, Madrid, 1995, p. 348). 
prudencia del magistrado la que permitiría decidir cuál de las dos formas de interdicción es la más adecuada.

No obstante, nuestro Código de Procedimiento Civil no establece expresamente la procedencia de esta acumulación alternativa de acciones y en doctrina se discute su admisibilidad. El argumento más fuerte en su contra es que la deducción de acciones en forma alternativa provocaría una indeterminación del objeto pedido en la demanda, lo que vulneraría la exigencia del $\mathrm{N}^{\circ} 5$ del art. 254 del Código de Procedimiento Civil, precepto que obliga al actor a determinar concretamente las peticiones que se someten al fallo del tribunal ${ }^{60}$.

La otra manera de interponer las acciones en concurso es la forma subsidiaria, llamada acumulación eventual. Es decir, se interpone una acción, pero para el caso de que ésta no sea acogida se deduce una segunda. Esta forma de acumulación está expresamente admitida por el art. 17 inc. $2^{\circ}$ del Código de Procedimiento Civil. Para que proceda esta acumulación es necesario que se cumplan los siguientes requisitos: $1^{\circ}$ la existencia de una pluralidad de acciones interpuesta por el demandante; $2^{\circ}$ que las acciones sean contradictorias entre sí y $3^{\circ}$ que todas las acciones se tramiten en un mismo proceso ${ }^{61}$.

Nos parece que estos requisitos se cumplen perfectamente en el caso de concurso de acciones de interdicción que estamos analizando. Por de pronto, ambas acciones se tramitan en el mismo procedimiento: juicio ordinario. Además, entre ellas existe la contradicción o incompatibilidad exigida, en el sentido de que no cabe que una misma persona sea a la vez interdicta por demencia y por disipación. Ambas acciones son excluyentes entre sí.

Esta fórmula, sí, obliga al actor a optar por cuál de las acciones preferiría que fuera acogida en primer lugar. La discrecionalidad del juez se aminora ya que sólo podrá acoger la demanda subsidiaria si declara improcedente la demanda principal.

No obstante, ante la incertidumbre existente tanto en doctrina como en jurisprudencia acerca de la aceptación de la acumulación alternativa, parece ser esta la fórmula más recomendable en la práctica.

\section{SituACión DE LA PERSONA ADICTA A LA COCAÍNA}

\section{Posibles trastornos mentales relacionados con el consumo de cocaína}

La tipificación y clasificación de los trastornos mentales ha sido intentada por un Manual elaborado bajo los auspicios de la American Psychiatric Association y que lleva por título DSM, Diagnostic and Statistical Manual of Mental Disorders y que en castellano

${ }^{60}$ En contra de la acumulación alternativa existe una sentencia de Corte Suprema de 31 de diciembre de 1910, Revista de Derecho y Jurisprudencia t. 9, sec. $1^{\mathrm{a}}$, p. 13, pero a favor se aduce la sentencia de Corte de Apelaciones de Santiago de 30 de diciembre de 1963, Revista de Derecho y Jurisprudencia t. 52, sec. $2^{\text {a }}$, p. 1. Romero Seguel, A., La acumulación inicial de acciones (Artículos 17 y 18 del Código de Procedimiento Civil), Conosur, Santiago, 2000, pp. 122-123, se inclina por la procedencia de la acumulación alternativa en los casos excepcionales en que se pide un mismo derecho a través de distintas acciones.

${ }^{61}$ Romero Seguel, A., ob. cit., p. 87. 
se conoce como Manual diagnóstico y estadístico de los trastornos mentales ${ }^{62}$. Este manual es revisado periódicamente para perfeccionar y actualizar su contenido. Actualmente, la edición vigente es la cuarta publicada en 1994, pero luego revisada el año 2000, y por ello se le denomina DSM-IV-TR (Text Revision). La próxima edición del DSM, el DSM-V, se espera para el año 2013.

Otro instrumento que suele utilizarse es la Clasificación estadística internacional de enfermedades y otros problemas de salud, llevada a cabo por la Organización Mundial de la Salud. La vigente fue aprobada por los Estados miembros de la organización en 1994, y se le conoce por ICD-10, International Classification of Diseases, o en castellano, CIE-10. El capítulo V, Códigos F00 a F99, corresponde a los trastornos mentales y del comportamiento ${ }^{63}$.

El DSM contiene todo un capítulo dedicado a los "Trastornos relacionados con sustancias”. Las sustancias pueden referirse a drogas de abuso, medicamentos o tóxicos. Entre las drogas de abuso figuran el alcohol, alucinógenos, anfetaminas, cafeína, cannabis, cocaína, nicotina, opioides, y otras. Se distinguen dos grupos: los trastornos por consumo de sustancias y los trastornos inducidos por sustancias. Estos últimos son, por ejemplo, la intoxicación, la abstinencia, el delirium inducido por sustancias, demencia persistente y otras. En cambio, el primer grupo, trastorno por consumo de sustancias, se divide en dos subclases: dependencia de sustancias y abuso de sustancias.

El abuso de sustancias se caracteriza esencialmente por "un patrón desadaptativo de consumo de sustancias manifestado por consecuencias adversas significativas y recurrentes relacionadas con el consumo repetido de sustancias" ${ }^{\text {64 }}$. Más allá del abuso, se encuentra la dependencia de sustancias, cuya característica esencial consiste en "un grupo de síntomas cognoscitivos, de comportamiento y fisiológicos que indican que el individuo continúa consumiendo la sustancia, a pesar de la aparición de problemas significativos relacionados con ella"65.

Para diagnosticar el trastorno de dependencia de sustancias se requiere la concurrencia de al menos tres de los ítems siguientes en un período continuado de doce meses:

1) Tolerancia: el sujeto necesita cantidades mayores de la sustancia para lograr el efecto deseado.

2) Abstinencia: se produce un síndrome de abstinencia.

3) La substancia es tomada con frecuencia en cantidades mayores o durante períodos más largos de lo que inicialmente se pretendía.

4) Deseo persistente o esfuerzos infructuosos de controlar o interrumpir el consumo.

5) Empleo de mucho tiempo en actividades relacionadas con la obtención de la sustancia.

6) Reducción de actividades sociales, laborales o recreativas.

${ }^{62}$ DSM-IV-TR, Manual diagnóstico y estadístico de los trastornos mentales, texto revisado, edición española dirigida por Juan J. López-Ibor Aliño y Manuel Valdés Miyar, Masson, Barcelona, 2003.

${ }^{63}$ La versión vigente de 2007 puede consultarse en línea en el sitio: http://apps.who.int/classifications/ apps/icd/icd10online (consulta: 27 de diciembre de 2010).

${ }^{64}$ DSM-IV-TR, p. 225.

${ }^{65}$ DSM-IV-TR, p. 218. 
7) Continuación del consumo a pesar de tenerse conciencia de problemas psicológicos o físicos que parecen causados o exacerbados por el consumo ${ }^{66}$.

Este cuadro general es especificado para la dependencia de cocaína. El DSM-IV-TR señala que "la cocaína posee efectos eufóricos y puede dar lugar a dependencias tras su consumo durante breves períodos de tiempo" ${ }^{\circ 7}$.

La clasificación del OMS, el CIE-10, contiene el código F14 referido a los "Trastornos mentales y del comportamiento debidos al uso de cocaína”. Aquí se incluyen la intoxicación aguda, el uso nocivo y el síndrome de dependencia.

En ambos instrumentos, se contempla que el consumo de cocaína puede llevar a enfermedades mentales de mayor gravedad. Así, el DSM-IV-TR contempla, dentro de las demencias, la demencia persistente inducida por sustancias (294.1), que puede producirse en asociación con sustancias inhalantes ${ }^{68}$. El CIE-10 incluye entre las formas de clasificación del código F-14 (trastornos debidos al consumo de cocaína) incluso síndromes de amnesia o psicóticos.

Para la aplicación en Chile de estos criterios, debe considerarse que la Resolución No 766, exenta, Ministerio de Salud, de 21 de julio de 2003, “Aprueba nómina de los trastornos mentales y del comportamiento, de la Clasificación Internacional de Enfermedades de la Organización Mundial de la Salud 10 a revisión”, consigna expresamente el F14, esto es, "Trastornos mentales y del comportamiento debidos al consumo de cocaína".

\section{Aplicación de la interdicción por disipación}

Parece claro que quien padece un trastorno derivado del consumo de cocaína incurrirá la mayor parte de las veces en los actos de dilapidación que autorizan la interdicción por esta causa.

El DSM-IV-TR dice que "Los sujetos con dependencia de cocaína suelen gastar mucho dinero en un espacio breve de tiempo y, como resultado de ello, pueden llegar a implicarse en robos, prostitución o negocios con la droga, o solicitar anticipos para comprar la droga" ${ }^{69}$. Se agrega que a menudo los individuos que sufren esta dependencia necesitan descontinuar el consumo para descansar "o para obtener fondos adicionales" 70 .

Puede transcribirse igualmente parte de un estudio publicado en la Revista Neurológica de Chile por el investigador Juan Pérez sobre los consumidores de pasta base de cocaína. Según este estudio, con datos extraídos de la población chilena, el estímulo más importante para consumir (con un $82 \%$ de menciones) lo constituye la posesión de dinero. Agrega este estudio que "el problema mayor del consumo crónico es el descenso en la escala valórica y el cambio de conductas del adicto. Alrededor de los dos a tres meses de uso han comenzado por vender sus enseres personales o cambiarlos por PBC [Pasta Base de Cocaína]. Piden

\footnotetext{
${ }^{66}$ DSM-IV-TR, pp. 218-225.

${ }^{67}$ DSM-IV-TR, p. 282.

${ }^{68}$ DSM-IV-TR, pp. 191-193.

69 DSM-IV-TR, p. 282.

${ }^{70}$ DSM-IV-TR, p. 282.
} 
dinero prestado con una serie de engaños que no son vivenciados como tales por el usuario. Por el contrario, se dan a sí mismos explicaciones que les parecen muy convincentes: 'Ya lo voy a devolver', 'Es por un tiempo', 'Me hago un pololo (trabajo) y lo devuelvo', o piden a nombre de su familia sintiendo que esta va a responder por ellos. Los que trabajan gastan el presupuesto destinado a la familia con argumentos similares, o consideran que tienen derecho ya que es "su" dinero. Cuando se les acaban sus recursos, comienzan a sustraer objetos del hogar. Hasta un $46 \%$ de los consultantes han hurtado fuera del hogar cuando la ocasión se les ha dado y podrían llegar a la violencia para conseguir dinero y droga $(1,6 \%)$ " 71 .

La aplicación del régimen de la interdicción por disipación en los casos de drogadicción ha sido considerada adecuada por la Corte Suprema en el Oficio $\mathrm{N}^{\circ} 152$, de 22 de junio de 2009, por el cual se emite opinión sobre el Proyecto de Ley Boletín N N $^{\circ} 332-25^{72}$. El proyecto de ley propone agregar al art. 1447 del Código Civil un inciso que señale "Sin perjuicio de lo anterior, respecto de las personas que se encuentren afectadas por alguna adicción a sustancias o drogas estupefacientes o sicotrópicas productoras de dependencia física o síquica, las instituciones financieras o comerciales en que el afectado tenga fondos, líneas de crédito, tarjetas de crédito, débito o dispositivos empleados como medio de pago equivalente a la moneda, deberán abstenerse de permitir cualquier retiro de dichos fondos o créditos por parte del afectado". Se agrega que la dependencia a las sustancias o drogas debe acreditarse ante la institución financiera o comercial por medio de certificado médico presentado por el cónyuge, los hijos mayores de edad, ascendientes directos o, en su falta, colaterales hasta en el cuarto grado, tras lo cual, en el plazo de tres días, debe recurrirse al juez para iniciar "la acción de interdicción correspondiente".

La Corte estima inconveniente que la sola presentación de un certificado médico tenga un efecto tan drástico, y señala que la incapacidad que se busca "podría ser obtenida a través de la declaración de interdicción por disipación, por aquellos que se encuentren facultados legalmente para hacerlo, ya que les serviría de fundamento el hecho de que la persona adicta a las drogas, producto de su enfermedad, está gastando o dilapidando sus bienes en perjuicio de su persona y de su círculo más cercano" (Oficio No 152, 2009, N 4).

\section{Aplicación de la interdicción por demencia}

Sin perjuicio de lo anterior, opinamos que también los trastornos derivados del consumo de la cocaína, incluida la dependencia de ella, siendo una discapacidad mental, pueden dar lugar a la interdicción por demencia. Pero para ello será necesario acreditar que el afectado ha perdido la capacidad de dirigirse a sí mismo. El DSM-IV-TR señala que "Las responsabilidades laborales o familiares pueden abandonarse para obtener y

${ }^{71}$ Pérez, Juan, "Clínica de la adicción a pasta base de cocaína”, en Revista chilena de neuropsiquiatría, vol. 41, 2003, $\mathrm{N}^{\circ} 1$, disponible en el portal Scielo.cl

${ }^{72} \mathrm{El}$ proyecto de ley lleva por título "Establece incapacidad relativa respecto de las personas que sufran adicción a las drogas”, y fue presentado en la Cámara de Diputados, el 20 de mayo de 2009, por los diputados Marcelo Díaz, Ramón Farías, Carlos Montes y Jorge Tarud. 
consumir la droga. A esto se unen, con frecuencia, complicaciones físicas o mentales como ideación paranoide, comportamiento agresivo, ansiedad, depresión y pérdida de peso"73. Esto será más seguro en los casos graves en que el trastorno ha pasado de mera dependencia a una demencia persistente inducida por sustancias o en que la dependencia pasa a adquirir rasgos de psicopatía. En el estudio de Juan Pérez, se advierte que "lo que más llama la atención es la pérdida de normativas sociales que vive el usuario, una pérdida que lo sume progresivamente en un estado de real desesperación y que no estaba en sus proyectos de vida. Se ve transformado en otro ser, situación que podríamos denominar síndrome sociopático" 74 .

Debe anotarse, sin embargo, que la jurisprudencia penal que aplica en forma más restrictiva la eximente contenida en el art. 10 No 1 del Código Penal, de locura o demencia, ha señalado que la dependencia o adicción a la cocaína no exime de responsabilidad penal, aunque sí puede constituir una atenuante de eximente incompleta ${ }^{75}$. Se observa, igualmente, que si comete el delito mientras se encuentra intoxicado con la droga, si bien puede decirse que actúa privado de razón, tampoco se aplica la eximente ya que dicha situación

${ }^{73}$ DSM-IV-TR, p. 282.
${ }^{74}$ Pérez, J., ob. cit.
${ }^{75}$ C. Santiago, 7 de septiembre de 2000 , Gaceta Jurídica $\mathrm{N}^{\circ} 243$, p. 158. La Corte Suprema ha casado en el fondo la sentencia que no da mérito al informe psiquiátrico que da cuenta de la dependencia a la droga del inculpado y no acoge así la atenuante del art. $11 \mathrm{~N}^{\circ} 1$ del Código Penal: "Que al no haber extraído de los elementos de juicio indicados, la consecuencia que naturalmente fluía de ellos, no se ha llegado a la conclusión apropiada que, precisamente se desprende del análisis individual y comparativo de los diferentes antecedentes del proceso, en especial de los informes antes referidos, de lo que se sigue que la sentencia ha incurrido en error de derecho, pues, aun cuando calificó el hecho punible y la participación con arreglo a la ley, ha desestimado la atenuante de responsabilidad del artículo $11 \mathrm{~N}^{\circ} 1$, en relación con el artículo 10 $\mathrm{N}^{\circ} 1$, ambos del Código Penal, imponiendo a la encartada una pena más grave que la que le corresponde de acuerdo a la ley. En efecto, la correcta ponderación de los diferentes informes de adicción y psiquiátricos, en uso de las reglas de la sana crítica, llevan a establecer que a la fecha en que incurrieron los hechos F. L. D. S., no se encontraba totalmente privada de razón, pero su voluntad estaba determinada por sus trastornos de adicción a drogas que causan graves trastornos a la salud humana; hecho que si bien no tiene los caracteres para eximirle de responsabilidad penal, sí representan una entidad suficiente para acreditar la minorante del artículo $11 \mathrm{~N}^{\circ} 1$ del Código punitivo, en relación con el artículo $10 \mathrm{~N}^{\circ} 1$ del mismo cuerpo legal, desde el momento que la procesada, por causas que no pueden calificarse de totalmente conscientes, realizó la conducta por la que se le acusó" (C. Sup. 21 de septiembre de 1997, Rol No 310-98, Legal Publishing $\mathrm{N}^{\circ}$ 14784). En el mismo sentido, en el nuevo proceso penal, puede verse la sentencia del Tribunal Penal Oral de Viña del Mar, 6 de marzo de 2006, RUC Nº500127061-5: “estos Jueces son de parecer, que favorece al imputado la atenuante del artículo $11 \mathrm{~N}^{\circ} 1$ del Código Penal, en relación con la eximente del artículo $10 \mathrm{~N}^{\circ} 1$ del mismo cuerpo legal, ya que ha quedado acreditado que el acusado padece de un daño orgánico cerebral a causa de su adicción a las drogas desde temprana edad, y que en el caso concreto que nos ocupa, se vio afectada su voluntad para abstenerse de cometer el delito de robo de que se trata, ya que era esa la forma de obtener recursos y proveerse de la droga" (cons. 13º); la sentencia del Tribunal Penal Oral, 7 de marzo de 2007, RUC Nº500676546-9, que aplica la atenuante al imputado diagnosticado de trastorno bipolar, deterioro orgánico cerebral y adicción a la pasta base de cocaína: "Esa anormalidad psíquica constituye una circunstancia que limita su libertad y reduce respecto de él la exigencia de un comportamiento distinto, circunstancia que necesariamente debe ser considerada al momento de fijar, en la pena, el reproche personal que su conducta merece" (cons. $11^{\circ}$ ). 
ha sido provocada por la misma voluntad del imputado y no por causas independientes como requiere la norma ${ }^{76}$.

\section{Solución ante la duplicidad de regímenes aplicable}

Cabe aplicar ahora lo que se ha determinado de manera general para los casos de concurso o concurrencia de regímenes y señalar que, ante un caso de un consumidor de cocaína, cuyo trastorno mental está fehacientemente diagnosticado por facultativos y sus actos de dilapidación debidamente comprobados, el juez debería ponderar el grado de intervención en su autonomía personal que resulta adecuado para una mejor protección del afectado. En principio, y atendida la tendencia a mantener los derechos del discapacitado incluso en el ejercicio de su capacidad jurídica, deberá inclinarse por la interdicción por disipación.

Pero si se estima que el trastorno que sufre la persona consumidora de cocaína es de tal entidad que le impide conservar una adecuada dirección de su misma persona, y ha perdido toda capacidad de autogobierno, será procedente la interdicción por demencia.

Debe notarse que tanto en uno como en otro caso la decisión podría ser variada si el desarrollo del trastorno modifica las circunstancias. Así, una persona que hubiera sido primeramente interdicta por disipación cuya patología se agrava, podría ser más tarde interdicta por demencia. Y, por el contrario, si la enfermedad remite y se observa un mayor grado de autodominio del afectado, él mismo o las personas habilitadas podrían pedir su rehabilitación como demente, aunque declarando la interdicción por disipación. Si existe mejoría completa o previsiblemente duradera podría conseguir que se le reponga en la libre administración de su persona y bienes y se cancele toda interdicción.

\section{CONCLUSIONES}

A modo de síntesis, podemos enumerar como conclusiones de este trabajo, las siguientes:

$1^{a}$ ) En la situación de personas afectadas por trastornos de dependencia a sustancias, especialmente de la cocaína, pueden concurrir los requisitos establecidos por la ley tanto de la interdicción por disipación como de la interdicción por demencia.

$2^{a}$ ) Ante un concurso de regímenes debe optarse por aquel que más se adecua a la situación actual del afectado, teniendo en consideración que existe una fuerte tendencia

${ }^{76}$ Se aplica la doctrina de las acciones libres en su causa. Por ejemplo, el Tribunal Penal Oral de Concepción, 19 de noviembre de 2008, RUC No 0700827848-7, ha dicho que "en el evento de haber actuado [el imputado] bajo los efectos de la droga, también podría considerarse que se trata de una acción libre en su causa (actio liberae in causa) que, por ende, no lo exoneraría ni aminoraría su responsabilidad y si a ello sumamos que la causa de la supuesta privación temporal y parcial de la razón sería el consumo voluntario de cocaína, se sustrae el elemento básico de la eximente cual es que la privación de razón sea por causas independientes de la voluntad del sujeto" (cons. $21^{\circ}$, n. 4 in fine). 
en derecho comparado, internacional y de legislación interna referida a la discapacidad mental, a conservar lo más posible la autonomía personal del incapaz.

$\left.3^{a}\right)$ Si se decreta la interdicción por disipación habría que estudiar si conviene que el curador le proporcione una cantidad de dinero para su libre administración, sin poner en riesgo su recaída en el consumo de la droga.

$4^{\mathrm{a}}$ ) Si se pretende interponer las dos acciones, lo más recomendable es que se aplique la acumulación eventual o subsidiaria. En tal caso, debería plantearse en lo principal la acción de interdicción por demencia, que es la más grave y la más compleja de acreditar ante el juez (sobre todo si hay contradicción del demandado), e interponer en subsidio la acción de interdicción por disipación o prodigalidad.

\section{BiBLIOGRAFÍA}

Albaladejo, Manuel, Derecho Civil I: Introducción y parte general, Bosch, $15^{\text {a }}$ edic., Barcelona, 2002. Alessandri Besa, Arturo, La nulidad y la rescisión en el Derecho Civil chileno, Edit. Jurídica de Chile, $3^{\text {a }}$ edic., Santiago, 2008.

Barcia Lehmann, Rodrigo, Lecciones de Derecho Civil chileno I: Del acto jurídico, Editorial Jurídica de Chile, Santiago, 2007.

Borda, Alejandro, "La capacidad", en La persona humana, Guillermo A. Borda (dir.), La ley, Buenos Aires, 2001, pp. 167-194.

Breccia, U.; Bigliazzi, L.; Natoli, U.; Busnelli, F., Derecho Civil: Tomo I volumen I: Normas, SUJETOS Y RELACIÓN JURÍDICA, trad. Fernando Hinostrosa, Universidad Externado de Colombia, Bogotá, 1992.

Claro Solar, Luis, Explicaciones de Derecho Civil chileno y comparado, reimp. Editorial Jurídica de Chile, Bogotá, 1992.

De Castro y Bravo, Federico, Derecho Civil de España, Instituto de Estudios Políticos, Madrid, 1952; reimp. Thomson Civitas, Madrid, 2008.

DSM-IV-TR, Manual diagnóstico y estadístico de los trastornos mentales, texto revisado, edición española dirigida por Juan J. López-Ibor Aliño y Manuel Valdés Miyar, Masson, Barcelona, 2003.

Frigerio Castaldi, César y Pizarro Borgoño, Álvaro, "Incapacidad civil y representación legal del enfermo mental recluido en un establecimiento psiquiátrico", en Familia y personas, Enrique Barros coord., Editorial Jurídica de Chile, Santiago, 1991.

Fueyo Laneri, Fernando, Derecho Civil VI: Derecho de Familia, Universo, Santiago, 1959.

Goubeaux, Gilles, Les personnes, en Traité de Droit Civil, Jacques Ghestin dir., L.G.D.J., Paris, 1989.

Heredia Puente, Mercedes y Fábrega Ruiz, Cristóbal, Protección legal de incapaces, Colex, Madrid, 1998.

Larraín Ríos, Hernán, Lecciones de Derecho Civil, Editorial Jurídica de Chile, Santiago, 1994.

León Hurtado, Avelino, La voluntad y la capacidad en los actos jurídicos, Edit. Jurídica de Chile, $3^{\mathrm{a}}$ edic., Santiago, 1979.

Lyon Puelma, Alberto, Personas naturales, Ediciones Universidad Católica de Chile, $3^{\mathrm{a}}$ edic., Santiago, 2007.

Mattera, Marta del Rosario y Noya, Gustavo Eduardo, "Los inhabilitados", en La persona bumana, Guillermo A. Borda (dir.), La ley, Buenos Aires, 2001, pp. 227-247.

Meza Barros, Ramón, Manual de Derecho de la Familia, Edit. Jurídica de Chile, $2^{\mathrm{a}}$ edic., Santiago, 1979. 
Pérez de VArgas MuÑoz, José, "El sistema italiano de protección de las personas privadas de autonomía”, en Revista de Derecho Privado (España), noviembre-diciembre 2010, pp. 3-26.

PÉrez, JuAn, "Clínica de la adicción a pasta base de cocaína”, en Revista chilena de neuropsiquiatría, vol. 41, 2003, $\mathrm{N}^{\circ} 1$, disponible en el portal Scielo.cl

Ramos Chaparro, Enrique, La persona y su capacidad civil, Tecnos, Madrid, 1995.

Ramos Pazos, René, Derecho de Familia, Editorial Jurídica de Chile, 6a edic., Santiago, 2007.

Romero Seguel, Alejandro, La acumulación inicial de acciones (Artículos 17 y 18 del Código de Procedimiento Civil), Conosur, Santiago, 2000.

Rossel Saavedra, Enrique, Manual de Derecho de Familia, Edit. Jurídica de Chile, $7^{a}$ edic. actualizada y corregida por María Dora Martinic y Graciela Weinstein, Santiago, 1993.

Somarriva Undurraga, Manuel, Derecho de Familia, Nascimento, Santiago, 1963.

Subsecretaría de Salud Pública, División de Prevención y Control de Enfermedades, Departamento de Salud Mental, Estudio sobre legislación chilena y salud mental, Gobierno de Chile, Organización Panamericana de la Salud, Santiago, 2008. 